\title{
Research Paper \\ Efficasy of group metacognitive therapy on emotional self-regulation and ego strength of anxious students
}

\author{
Zohreh Rafezi $^{1}$, Golfam Pirabbasi ${ }^{2}$, Hossein Eskandari ${ }^{3}$ \\ 1. Assistant Professor, Department of Psychology, Faculty of Psychology and Educational Sciences, Allameh Tabataba'i University, \\ Tehran, Iran. \\ 2. M.A. of Clinical Psychology, Department of Psychology, Faculty of Psychology and Educational Sciences, Allameh Tabataba'i \\ University, Tehran, Iran. \\ 3. Professor, Department of Psychology, Faculty of Psychology and Educational Sciences, Allameh Tabataba'i University, Tehran,
} Iran.

Citation: Rafezi Z, Pirabbasi G, Eskandari H, Khodabakhshi Koolaee A. Efficasy of group metacognitive therapy on emotional selfregulation and ego strength of anxious students. $\mathrm{J}$ of Psychological Science. 2022; 20(108): 2239-2254.

URL: https://psychologicalscience.ir/article-1-1192-fa.html
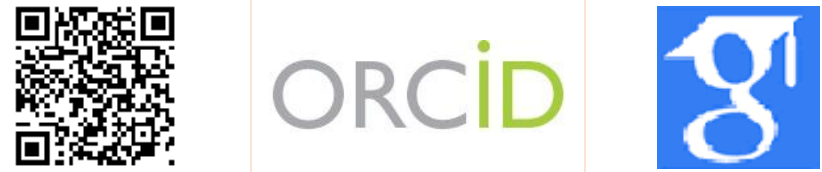

$\underline{10.52547 / J P S .20 .108 .2239}$

\section{A R T I C L E I N F O A B S T R A C T}

Keywords:
Emotional
regulation,
Ego strength,
Group metacognitive
therapy,
Anxiety

Received: 23 Mar 2021 Accepted: 08 May 2021 Available: 20 Feb 2022
Background: According to studies, emotional self-regulation and ego power are effective variables on anxiety, which is effective in organizing adaptive behavior and preventing negative emotions. Metacognitive therapy is effective on beliefs related to thought control, self-regulation strategies and increasing my strength in anxious people, but there is a research gap in the group effectiveness of this treatment.

Aims: This study aimed to determine the effectiveness of group metacognitive therapy on emotional self-regulation and ego strength of anxious students.

Methods: This was a quasi-experimental study with a pretest-posttest design with a control group. The statistical population of the present study consisted of all students of Allameh Tabatabai and Shahid Beheshti Universities of Tehran in the academic year 2020-2021, from which 30 students were selected by sampling method and according to the inclusion and exclusion criteria as a sample. They were randomly divided into experimental $(n=15)$ and control $(n=15)$ groups. The experimental group received group metacognitive therapy wells and cartwright (2008) in 10 sessions of 45 to 60 minutes in the Green Way Psychology Clinic. The control group was also placed on a waiting list. The Psychological Inventory of Ego Strength (PIES) of Markstrom et al (1997) and emotional self-regulation questionnaire og the Hoffman et al (2010) were used to collect data. Data analysis using multivariate analysis of covariance.

Results: The results showed that group metacognitive therapy significantly increased hope (28.48), desire (59.05), goal (24.16), competence (44.64), loyalty (48.50), love (9.83), care (72.74), wisdom (10.24), adaptation (92.90), secrecy (27.65) and tolerance (33.95) of anxious students were effective $(\mathrm{p} \leq 0.001)$.

Conclusion: Overall, group metacognitive therapy can reduce anxiety by modifying misconceptions about uncontrollable anxiety, negative beliefs, and increasing self-esteem.

* Corresponding Author: Golfam Pirabbasi, M.A. of Clinical Psychology, Department of Psychology, Faculty of Psychology and Educational Sciences, Allameh Tabataba'i University, Tehran, Iran.

E-mail: golfam.pirabasii@gmail.com

Tel: (+98) 9125995480

2476-5740/ (C) 2021 The Authors. This is an open access article under the CC BY-NC-ND license

(https://creativecommons.org/licenses/by-nc/4.0/). 


\section{Extended Abstract}

\section{Introduction}

Anxiety, as a part of every human life, is present in all people in moderation and in this extent, it is considered as a compromised response (Goger, Rosenman and Gonzalez, 2020). One of the influential variables on students' anxiety is emotional self-regulation (Ader \& Erktin, 2010). Emotion regulation is a basic principle in initiating, evaluating and organizing adaptive behavior as well as preventing negative emotions and maladaptive behaviors (Adesola \& Li, 2018). Since emotion regulation plays a central role in the development of norm and weakness in it is an important factor in the development of mental disorders (Martín, OrtegaSánchez, Miguel \& Martín, 2021). Ego power is another important variable that can affect students' anxiety (Mishra, 2013). The power of the ego refers to my capacity to handle the conflicting demands of the institution, the superego, and the requirements of external reality, and to the extent that I am unable to strike a functional balance, the individual's personality will be impaired (Sobański et al., 2018). Patients' ego must have ways to cope with anxiety, to be effective in reducing stress and to be able to control events (Abood \& Idri, 2020).

Various therapies have been used for emotional selfregulation and ego power, but one of the new therapies for reducing anxiety is group metacognitive therapy. Metacognition is a multifaceted concept and refers to the knowledge or beliefs about thinking and the strategies that people use to regulate and control thought processes. In order to modulate cognitive and attention deficit disorder in patients undergoing psychological therapy, Wells has provided training and practice of metacognitive techniques with the aim of establishing attention control training with disconnected mindfulness techniques that are the opposite and incompatible with this syndrome (Ellis \& Hudson, 2014). In metacognitive therapy, unlike other cognitive therapies, the primary focus is not on assessing the reality of common negative beliefs. The therapist's metacognition for the treatment of anxiety does not seek to verify the patient's beliefs through the critique of affirmative and negative evidence, but helps him or her respond to angry thoughts by challenging metacognitive beliefs and eliminating the cognitive-attention syndrome. Respond to anger or worthlessness in a new way (Goger, Rozenman \& Gonzale., 2020).

Metacognitive group therapy as a new therapy can improve the disorder of emotional self-regulation and low ego strength of people with high anxiety (Sobański et al., 2018; Duch-Ceballos, Oliver Pece \& Skowron, 2020). In this regard, the present study was conducted to determine the effectiveness of group metacognitive therapy on self-regulation, emotional and ego strength of anxious students.

\section{Method}

The present study was quasi-experimental and pretest-post-test with a control group. The statistical population of the study included all students of Allameh Tabatabai and Shahid Beheshti universities in Tehran in the academic year 2019-2020. Due to the fact that the training in this study was done in groups and in the group, therapy based on the work of Wells and Cartwright (2008), the groups of 12 to 15 people used in this study were 30 people. The available form was selected with the criteria of entering and leaving the research and were randomly divided into two groups of 15 experimental and control.

In this study, 380 volunteer students completed the Beck Anxiety Inventory online to participate in the study; Then 30 student whose anxiety was a standard deviation above the average participated in this study. First, before the intervention, the pre-test was taken from the experimental and control subjects by the researcher. That is, participants completed the Ego Power Psychological Questionnaire and the Emotional Self-Regulation Questionnaire, and then the intervention was performed based on a treatment protocol of 10 sessions of 45 to 60 minutes by the researcher at the Green Way Psychology Clinic on the experimental group only and the control group received no treatment. did not. Finally, the subjects of both experimental and control groups filled in the mentioned questionnaires again in the post-test stage. 
Table 1. Results of univariate analysis of covariance on the mean post-test scores of dependent variables

\begin{tabular}{ccccccc}
\hline Variable & MS & Df & F & Sig & ETA & Power \\
\hline Hope & 42.51 & 1 & 28.48 & 0.001 & 0.62 & 0.99 \\
wish & 70.48 & 1 & 59.05 & 0.001 & 0.77 & 1 \\
Target & 45.12 & 1 & 24.16 & 0.001 & 0.58 & 0.99 \\
Competence & 44.94 & 1 & 44.64 & 0.001 & 0.72 & 1 \\
Loyalty & 81.73 & 1 & 48.50 & 0.001 & 0.74 & 1 \\
Love & 51.14 & 1 & 9.83 & 0.006 & 0.36 & 0.84 \\
Taking care & 146.71 & 1 & 72.74 & 0.001 & 0.81 & 1 \\
Wisdom & 43.85 & 1 & 10.24 & 0.001 & 0.37 & 0.85 \\
Compatibility & 128.13 & 1 & 92.90 & 0.001 & 0.84 & 1 \\
Concealment & 193.50 & 1 & 27.65 & 0.001 & 0.61 & 0.99 \\
Tolerance & 98.01 & 1 & 33.95 & 0.001 & 0.66 & 1 \\
\hline
\end{tabular}

\section{Results}

The mean age of study participants was 22.87 years $(\mathrm{SD}=3.5) .18$ participants were single and the rest $(7)$ were married. 3 people reported their economic situation as weak and 20 people and 7 people expressed their economic situation as moderate and good, respectively. In terms of degree, 21 were undergraduate students, 7 were graduate students and 2 were PhD students.

The results of analysis of covariance showed hope (28.48), desire (59.05), goal (24.16), competence (44.64), loyalty (48.50), love (9.83), care (74 / 72), wisdom (10/24), adaptability (92/90), stealth (27/65) and tolerance (33.95) are significant at the level of 0.05 . These findings indicate that there is a significant difference between the groups in these variables. Also, according to the calculated effect size, $62 \%$ of hope, $77 \%$ of desire, $58 \%$ of purpose, $72 \%$ of competence, $74 \%$ of loyalty, $36 \%$ of love, $81 \%$ of care, $37 \%$ of wisdom, $84 \%$ of compatibility, $61 \%$ Concealment and $66 \%$ of tolerance changes were due to the effect of the independent variable; As a result, it can be said that the effectiveness of group metacognitive therapy has significantly increased emotional self-regulation and the strength of the ego of anxious students.

\section{Conclusion}

The aim of this study was to determine the effectiveness of metacognitive therapy on emotional self-regulation and ego strength of anxious students. The findings of this study showed that group metacognitive therapy had an effect on the iguo strength of anxious students and caused an increase in the iguo strength of anxious students after the test.
Metacognitive therapy can help improve ego strength in anxious students by teaching mindfulness and increasing cognition of and understanding the psychological processes of self. Metacognitive therapy is a therapy that emphasizes emotional selfawareness and believes that people can consciously bring many cognitions, thoughts and even subconscious contents, so it can be a good treatment to be effective on the ego power of anxious people (Kim and Park, 2013). Since emotion regulation strategies are an important part of every person's life, it is not surprising that disturbance in emotion and its regulation can cause psychological damage. Inconsistent cognitive emotion regulation strategies such as rumination, self-blame, and catastrophizing are significantly associated with the severity of anxiety symptoms (Martin et al., 2021).

Overall, the results of the present study showed; Group metacognitive therapy has had an effect on ego strength and emotional self-regulation of anxious students and caused an increase in ego strength and emotional self-regulation of anxious students. In fact, it can be said that metacognitive group therapy made anxious students more aware of their emotions in stressful and anxious situations. It also helped anxious people to take steps to recognize their own and others' thoughts and feelings. 


\section{Ethical Considerations}

Compliance with ethical guidelines: This research is taken from Golfam Pirabbasi master's thesis at Allameh Tabatabai University. It should be noted that in this research, the researcher, after obtaining approval from the ethics committee, IR.ATU.REC.1399.053 conducted the research process.

Funding: This study was conducted without the financial support of any public or private institution or organization.

Authors' contribution: The first author is responsible for obtaining licenses, implementing protocols and questionnaires;
The second author is responsible for writing Persian and English abstracts, introduction and research background, and the third author is responsible for writing conclusions, sources and formatting.

Conflict of interest: This research has not had any conflict of interest for the authors.

Acknowledgments: The authors would like to thank all the people who participated in this study. 


\section{اثربخشى درمان فراشناختى كروهى بر خودنظمجريى هيجانى و قدرت ايگوى دانشجويان مضطرب}

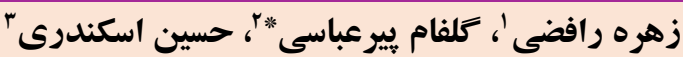

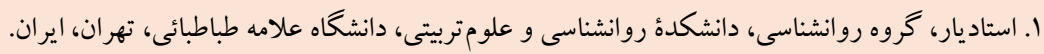

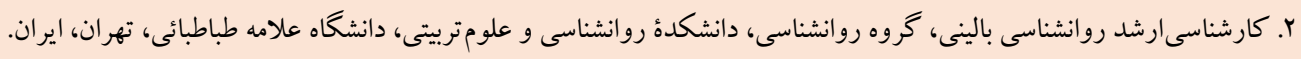

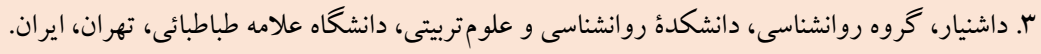
مشخصات مقاله

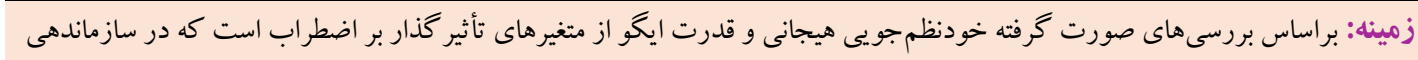

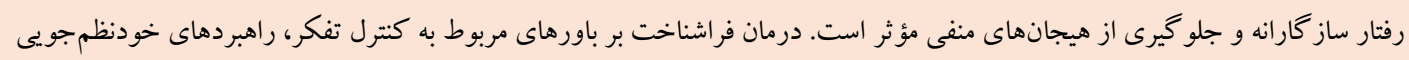

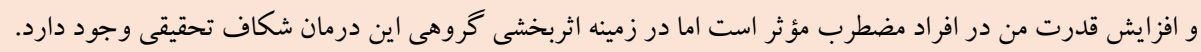

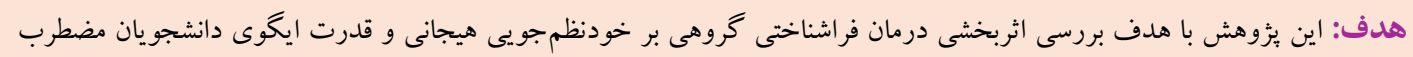

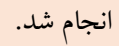

\section{جكيده}

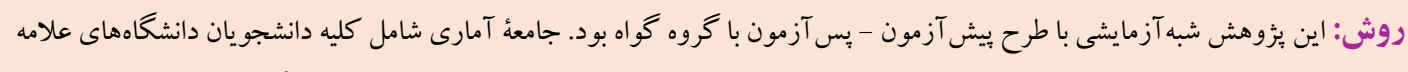

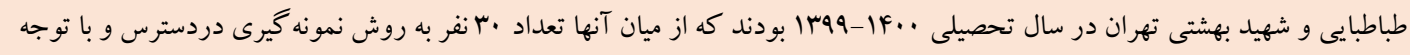

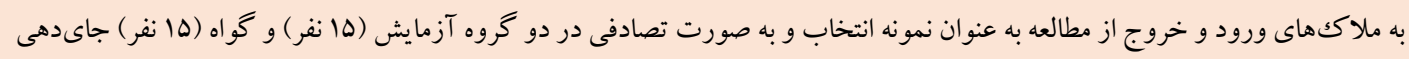

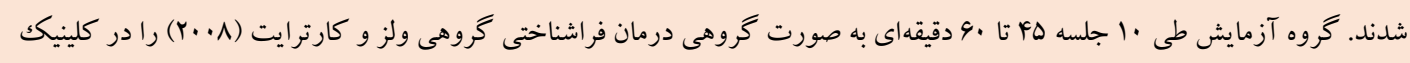

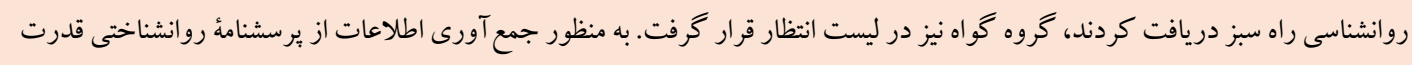

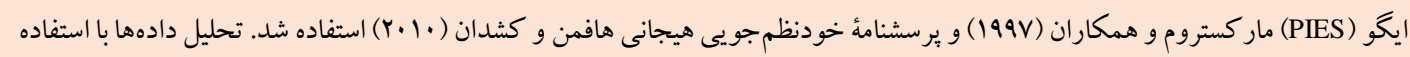

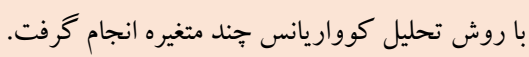

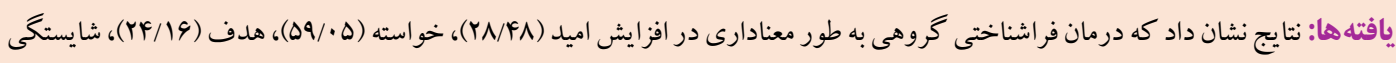

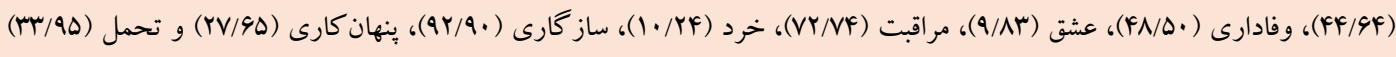

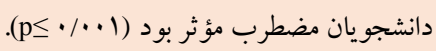

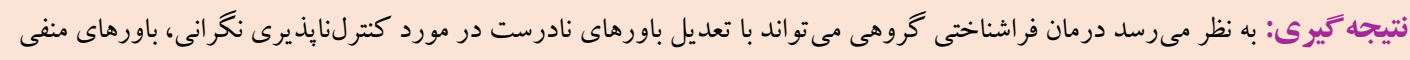

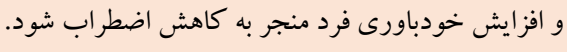

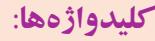
خونظمجويى هيجانى، قدرت ايكو، درمان فراشناختى گروهى،

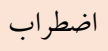

* نويسنده مسئول: كلفام يير عباسى، كارشناسىارشد روانشناسى بالينى، گروه روانشناسى، دانشكدة روانشناسى و علوم تربيتى، دانشكاه علامه طباطبائى، تهران، ايران. رايانه: golfam.pirabasii@gmail.com 
بررسى تنظيم هيجان و اضطراب رياضى در دانش آموزان برداختند. نتايج اين مطالعه مشخص كرد افرادى كه از راهبردهاى ناساز گارانه تنظيم هيجان استفاده مى كردند از اضطراب رياضى بالاترى برخوردار بودند.

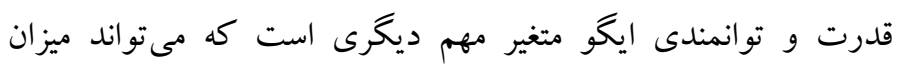

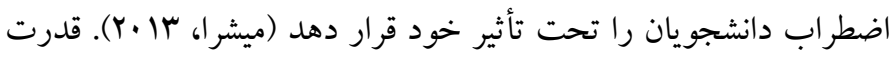
ايگو به ظرفيت من براى اداره تقاضاهاى متعارض نهاد، سويرايگو و مقتضيات واقعيت بيرونى اشاره دارد و به ميزانى كه من قادر به ايجاد تعادل

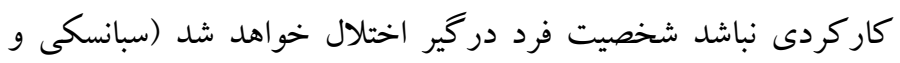

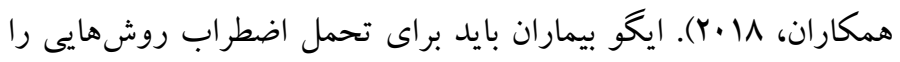
داشته باشد، تا در كاهش فشار روانى مؤثر واقع شود و بتواند رويدادها را

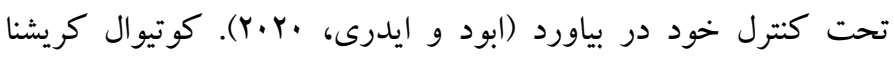
(Y.11)

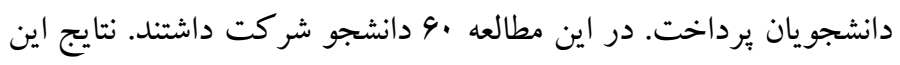
بثزوهش نشان داد دانشجويانى كه قدرت ايگو ضعيفترى داشتند از

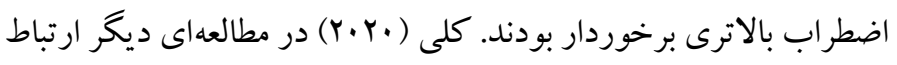

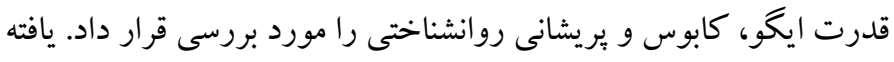

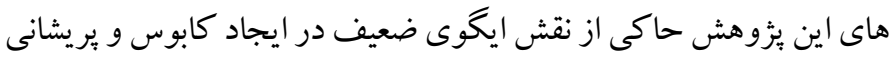
روانشناختى داشت.

براى خودنظمجويى هيجانى و قدرت ايخو درمانهاى گوناكونى مانند

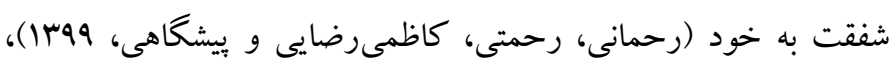

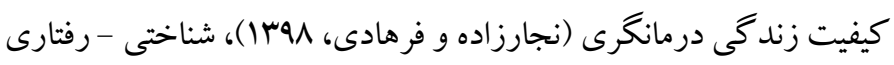

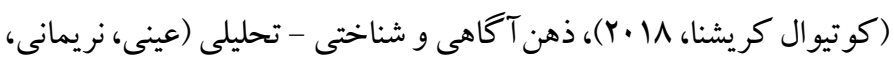

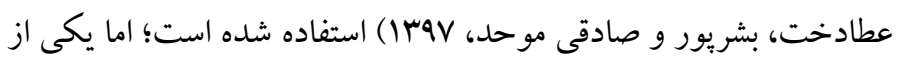
درمانهاى نوين براى كاهش اضطراب درمان فراشناختى گروهى است ونت

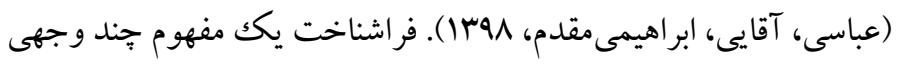
است و به دانش يا باورهاى مربوط به فكر كردن و راهبردهايى كه افراد از از آنها براى تنظيم و كنترل فر آيندهاى تفكر استفاده مى كنند، اشاره دارد. ولز به منظور تعديل نشانگان شناختى و توجهاى در بيماران تحت درئ درمان روانشناختى، آموزش و تمرين تكنيكهايى فراشناختى با هدف ايجاد آموزشهاى كنترل توجه با فنون ذهن آكاهى انفصالى كه نقطه مقابل و و

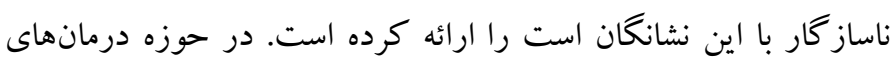

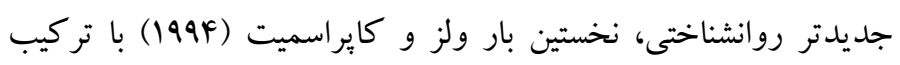

مقلفمه

اضطر اب بهمنزلهُ بخشى از زندگى هر انسان، در همهٔ افراد در حدّى اعتدال

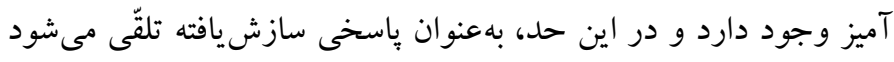

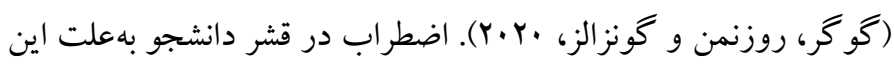
كه ضرورت حضور در اجتماعات آموزشى در برابر اساتيد و جنس مقابل

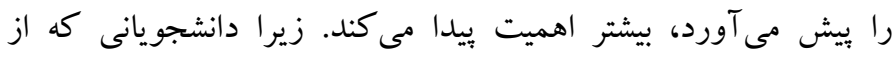

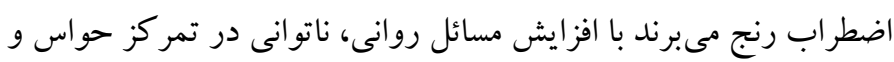

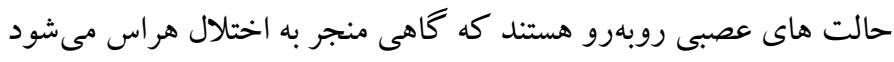

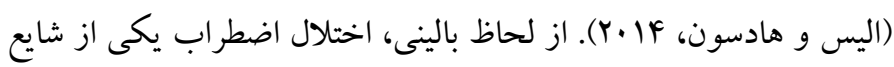

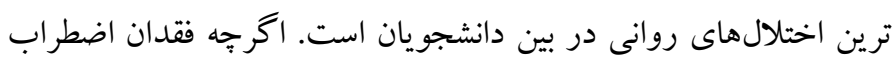

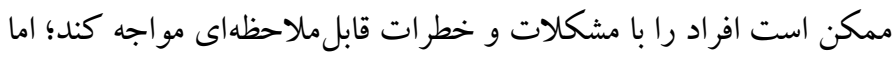

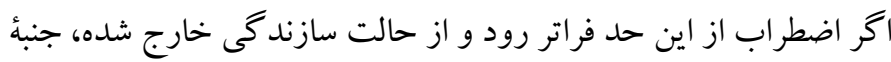

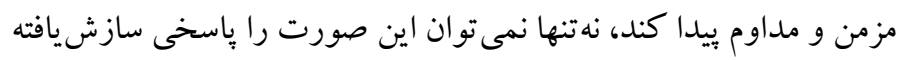

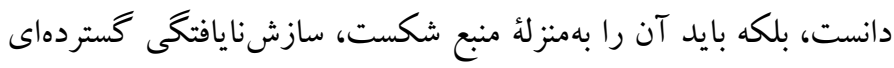

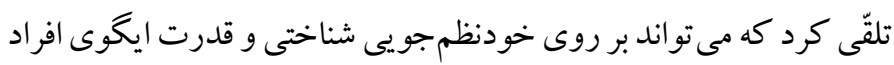

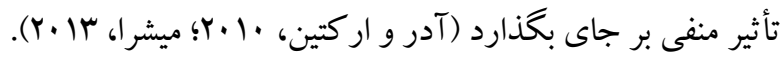

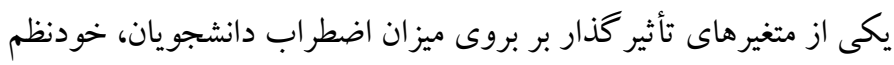

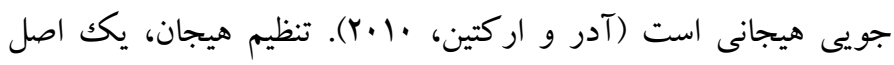

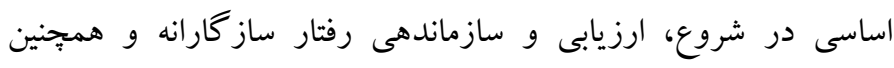

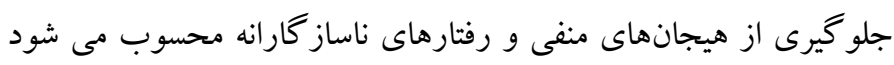

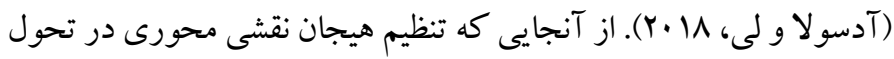

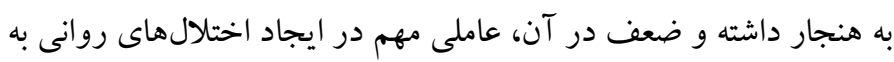

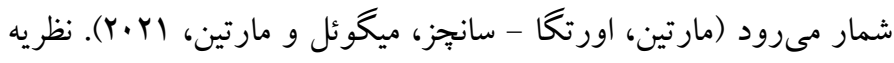

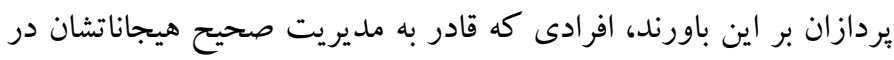
برابر رويدادهاى روزمره نيستند، بيشتر نشانهاى تشخيصى، اختلالهاى

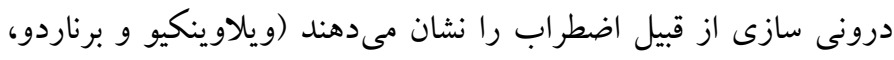

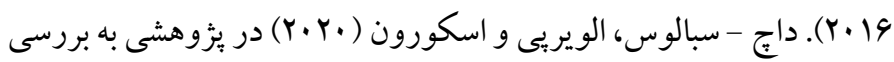

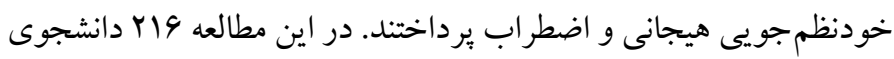

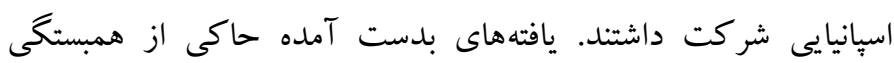

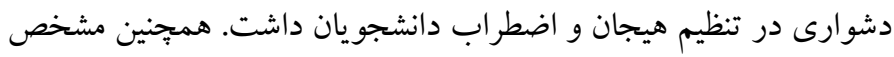

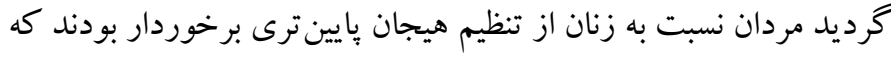

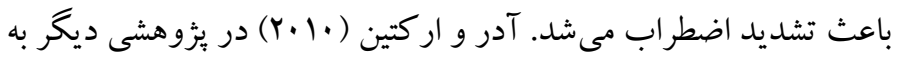


ايگوى پايين افراد داراى اضطراب بالا را بهبود ببخشد (سبانسكى و

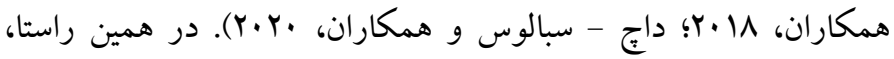

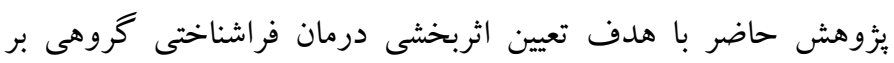
خودنظمجويى هيجانى و قدرت ايخوى دانشجويان مضطرب انجام شد.

روش

الف) طرح بثوهش و شر كت كند كان: بزوهش حاضر، شبه آزمايشى و

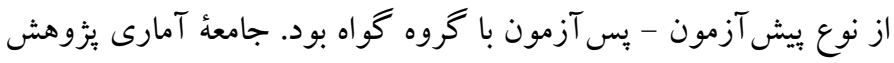
شامل كليه دانشجويان دانشگاههاى علامه طباطبائى و شهيد بهشتى تهران

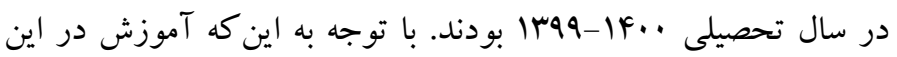

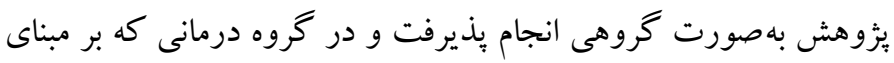

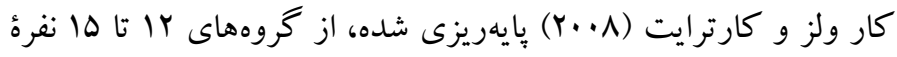
استفاده شده در اين ئزوهش نيز ·r نفر بهصورت در دسترس و با ملاككهاى

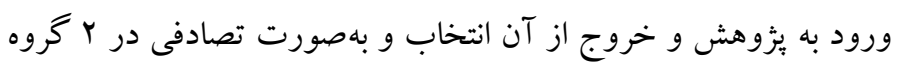
ها نفره آزمايش و گُواه قرار گر فتند.

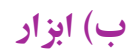

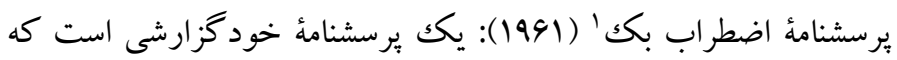

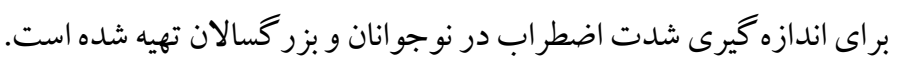
مطالعات انجامشده نشان مىدهند كه اين يرسشنامه از قابليت اعتماد و درستى بالايى برخوردار است. ضريب همسانى درونى آن (ضريب آلفا)

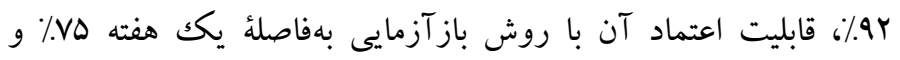

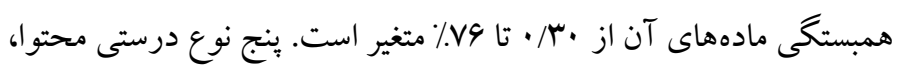

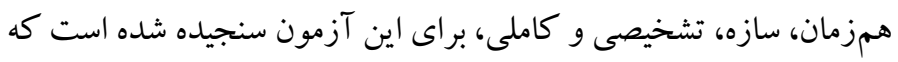

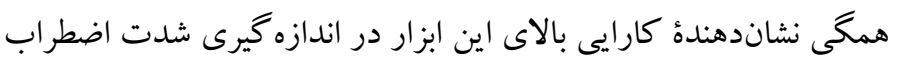
است. برخى تحقيقات در ايران در مورد خصوصيات روانسنجى اين آن آنس

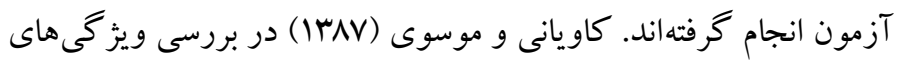

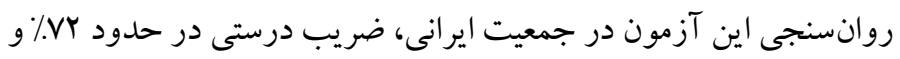

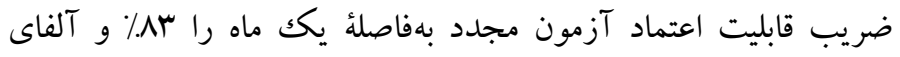
كرونباخ بو٪ را گزارش كردهاند. در اين بزوهش، ضريب آلفاى كرونباخ

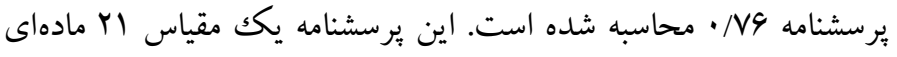

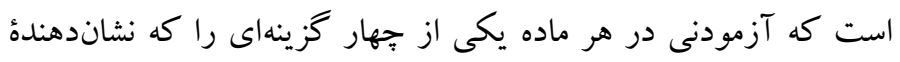

رويكرد طرحواره و يردازش اطلاعات، الكوى فر اشناختى را بر مبناى مدل عملكرد اجرايى خودتنظيمى، جهت تبيين و درمان اختلالات هيجانى

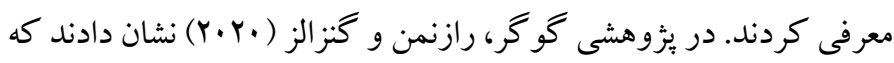
سطوح بالاى اضطر اب با مشكلات خودنظم جويى هيجانى در افراد مرتبط

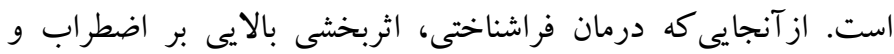

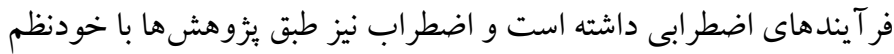
جويى هيجانى در ارتباط است، بهنظر مىرسد كه اين درمان براى بهبود خودنظمجويى هيجانى در افراد مضطرب مناسب باشد (كينيبرا، بلاستين،

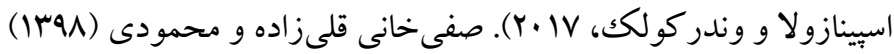

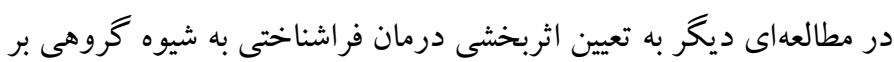

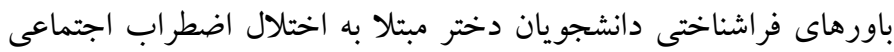

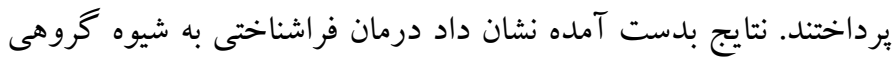

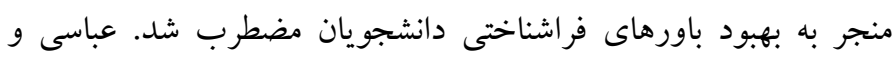

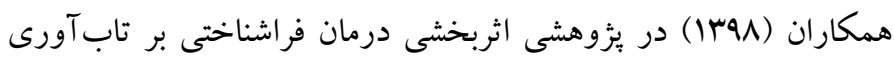

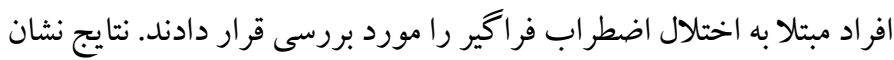
داد كه درمان فراشناختى بر تابآورى بيماران افراد مبتلا به اختلال

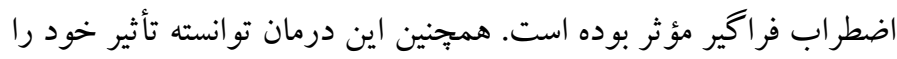
در زمان نيز به شكل معنادارى حفظ نمايد و ميزان تأثير آمارى درمان

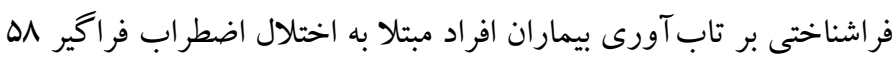
درصل بود. در درمان فراشناختى بر خلاف ساير درمانهاى شناختى تمركز اوليه بر

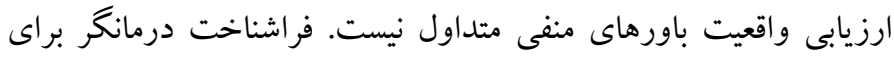

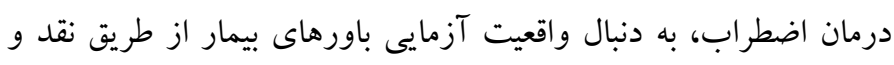

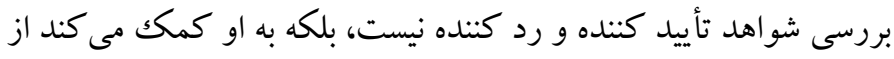
طريق جالش باورهاى فراشناختى و حذف سندرم شناختى - توجهى، در

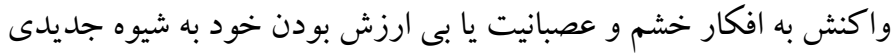

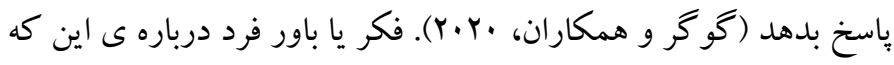

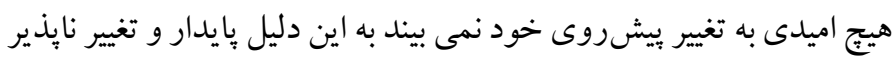

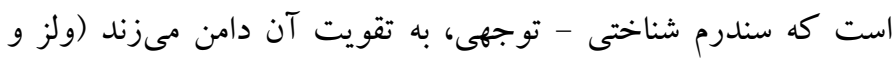

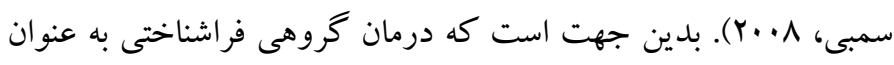
يكك درمانى نوين مىتواند اختلال در خودنظمجويى هيجانى و قدرت

1. Beck's Depression Inventory 
اعتماد كل براى اين برسشنامه در بثوهش شاكرمى، لطيفى و موسوى

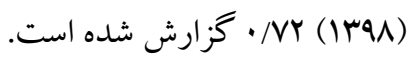

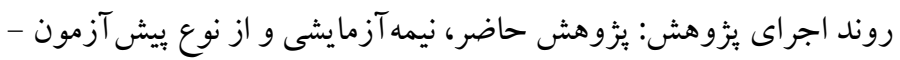

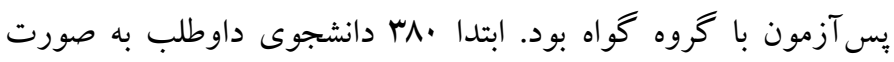

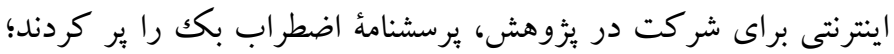

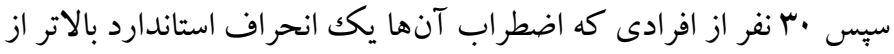
ميانگين بود، در اين بُزوهش شركت كردند. در ابتدا قبل از انجام مداخله،

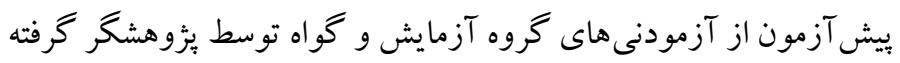

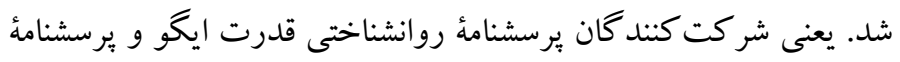

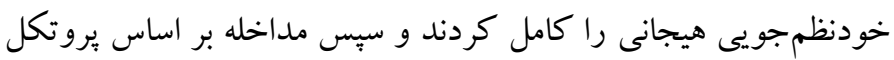

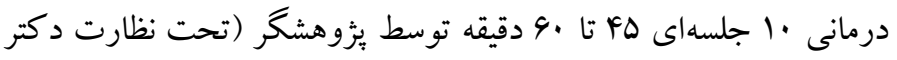
رافضى) در كلينيك روانشناسى راه سبز فقط روى گروه آزمايشى اجر اشد

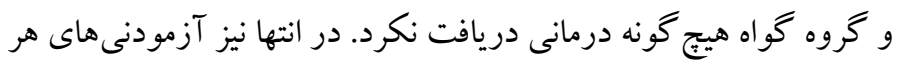

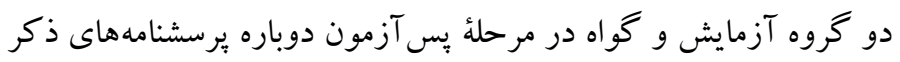

$$
\text { شده را بر كردند. }
$$

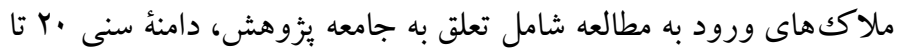
.

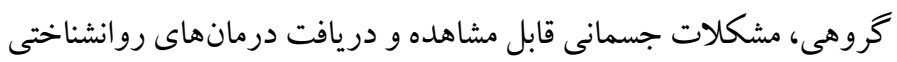

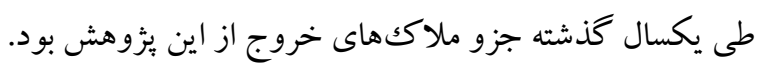

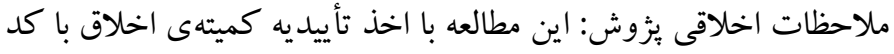

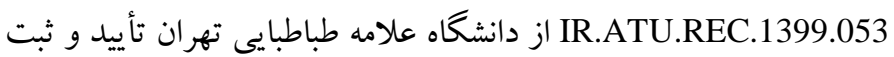
شد. بِ از هماهنكى هاى لازم، برسشنامه هاى مورد نظر به شر كت كنند گان

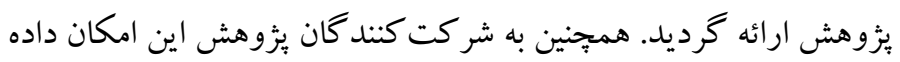
شد كه در هر لحظه از مطالعه كه تمايل داشتند، انصراف دهند. به منظور

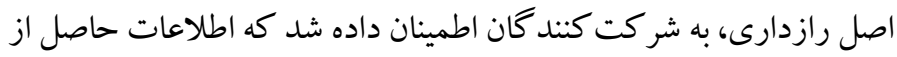

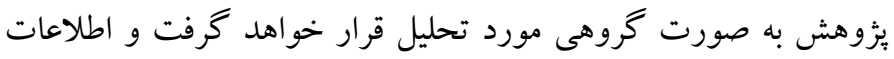

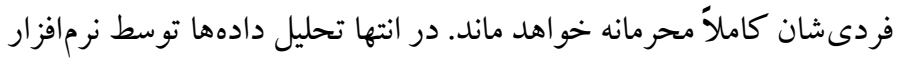
نسخه YF و با استفاده با روش تحليل كوواريانس (MANCOVA)

$$
\text { انجام گرفت. }
$$

يروتكل درمان فراشناختى گروهى: در يثزوهش حاضر، درمان فراشناختى

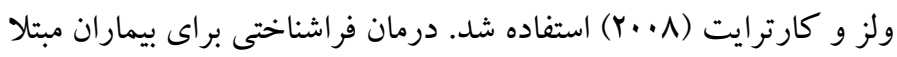

2. Emotional Self-Regulation Questionnaire
شدت اضطراب اوست را انتخاب مى كند. جهار گزينهُ هر سؤال در يكك طيف جهاربخشى از · تا ب نمره كذارى مىشود. هر يك از از مادههاى

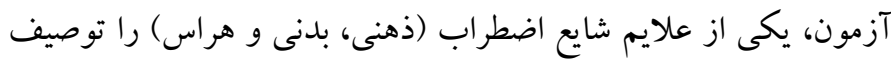

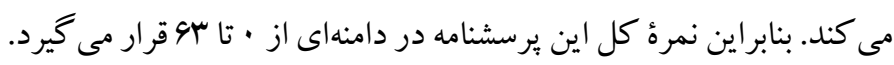

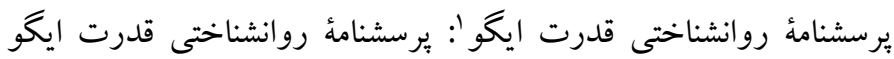
توسط مار كستروم و همكاران (199V) ساخته شده است. اين برسشنامه، هشت نقطة قدرت ايكو كه شامل اميد، خواسته، هدف، شايستخى، وفادارى، عشق، مر اقبت و خرد هستند را مى سنجد و داراى عاب سؤ ال است.

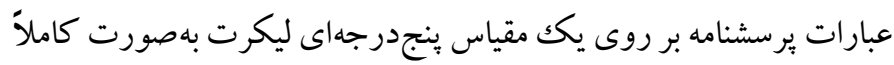

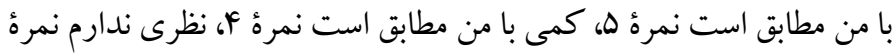

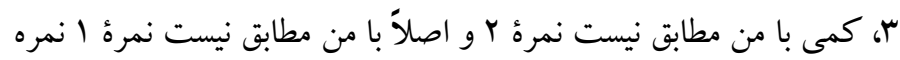

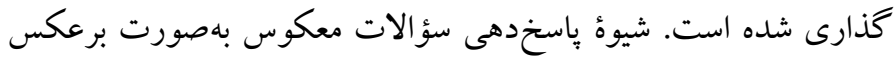

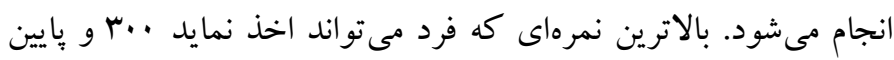

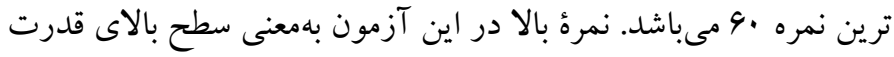

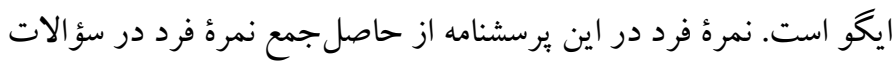
بهدست مى آيد. مار كستروم و همكاران (199V)، درستى صورى، محتوا و و

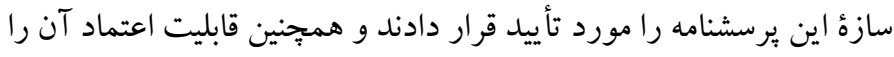

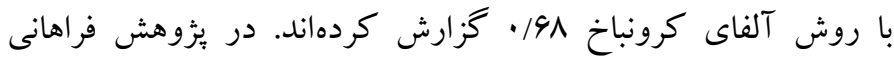

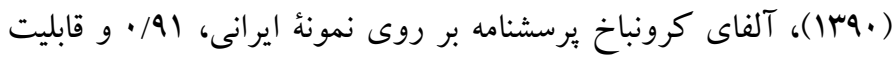
اعتماد دونيمهسازى مقياس، VV/ • گزارش شده است.

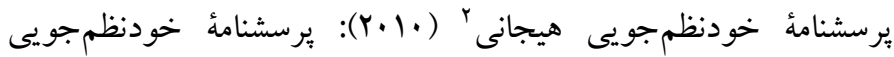

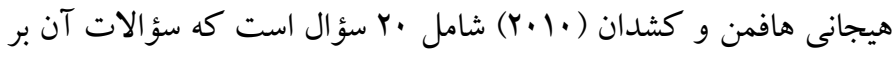

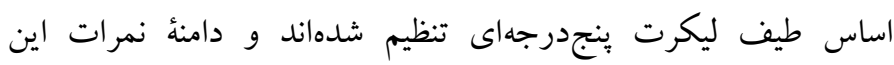

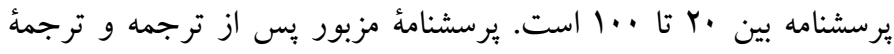
مجدد، از نظر درستى محتوايى در اختيار متخصصان روانشناسى مربوطه

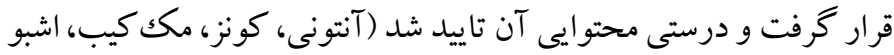

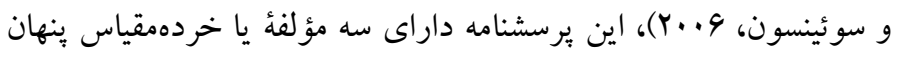

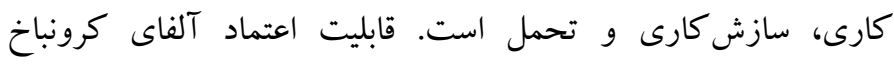

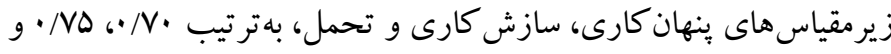

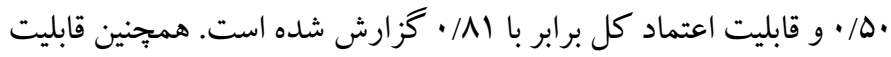

1. Psychosocial Inventory of Ego Strengths (PIES) 
و اقعيت بداند كه رفتار كند، آنها را صرفاً حوادثى ذهنى نيازمند بردازش ذهنى بيشترى نيست. تكليف افراد شامل تمرين تكنيككهاى فراشناختى

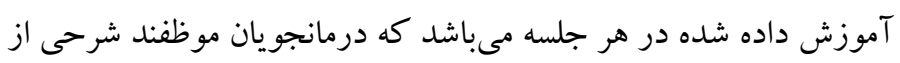
انجام تكاليف خود را در ابتداى هر جلسه بيان نمايند.

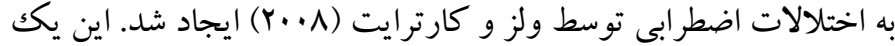

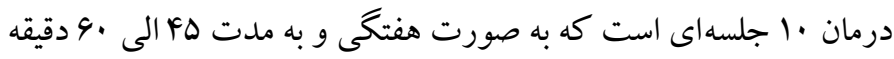

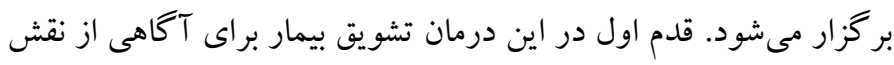

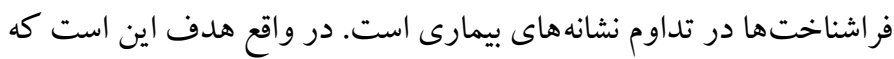

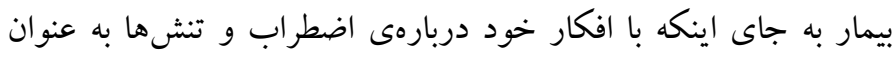

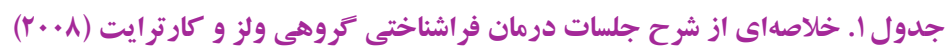

\begin{tabular}{|c|c|}
\hline محتوا & جلسات \\
\hline 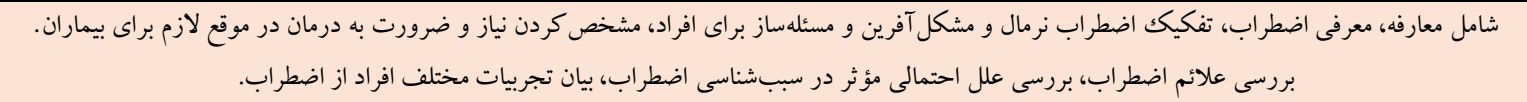 & جلسئ اول \\
\hline بررسى درمانهاى مختلف براى اضطراب، ارائهة توضيحاتى در مورد منطق درمان فراشناختى. تدوين فرمولبندى درمان و معرفى درمان فراشناختى & جلسة دوم \\
\hline 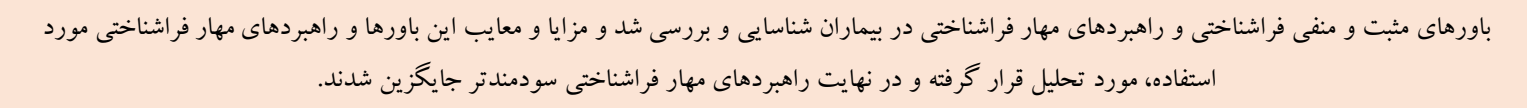 & جلسةُ سوم \\
\hline 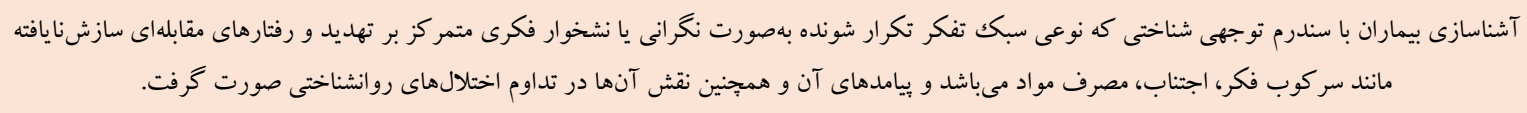 & جلسة جهارم \\
\hline تكنيك آموزش توجه، منطق تكنيك، ارزيابى اعتبار تكنيك، درجهبندى توجه معطوف به خود، رهنمودهاى اساسى براى آموزش تكنيك توجه و دريافت بازخورد از & جلسة يُنجم \\
\hline 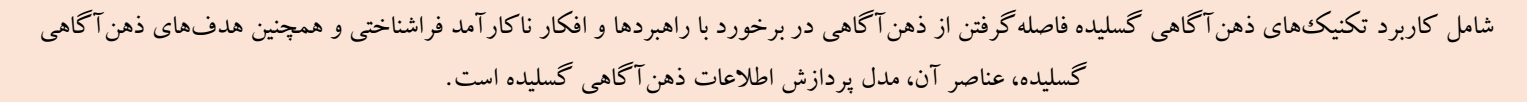 & جلسة ششم \\
\hline جهارتا از ده تكنيك ذهن آكاهى شامل هدايت فراشناختى، تكليف تداعى آزاد، تكليف تجسم پلنك،، آزمايش سر كوبى -عدم سر كوبى به شركت كند كان آموزش & جلسة هفتم \\
\hline شامل آموزش سه تكنيك ديخر از ده تكنيك ذهن آكاهى گسليده شامل: استعارة ابرهاى گذرا، استعارة كودكك متمرد، استعارة قطار مسافرى بوده است. & جلسة هشتم \\
\hline سه تكنيكى باقى ماندة حلقة كلامى، گستخىى، مشاهده كردن خود و تكنيكى خياليردازى به شر كت كند كان آموزش داده شد. & جلسة نهم \\
\hline شامل آماده كردن اعضا براى اختتاميه، شناسايى موانع موجود در به كار گيرى روشها و تكنيكها، علتيابى و رفع آن و در نهايت نتيجه گيرى بوده است. & جلسة دهم \\
\hline
\end{tabular}

جدول r ارائه شده است. همجِين در اين جدول نتايج آزمون شاييرو -

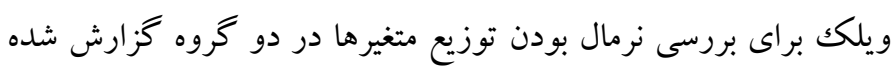

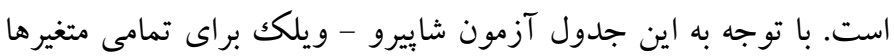
معنى دار نمىباشد. لذا مى توان نتيجه كرفت كه توزيع متغير ها نرمال است.

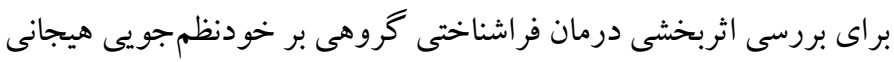

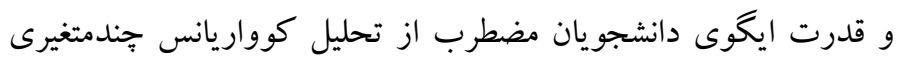
استفاده شد. نتايج آزمون لوين براى بررسى همخنى واريانس متغيرهاى

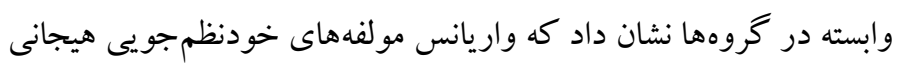

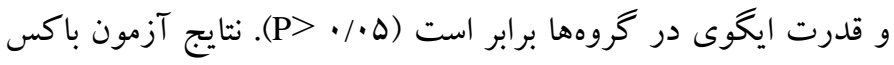
براى بررسى برابرى ماتريس كوواريانس متغيرهاى وابسته در بين گرووه

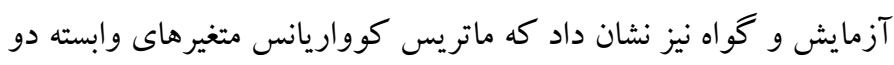

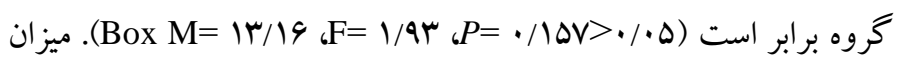

يافته ها در هر بزوهشى، آمار توصيفى و بررسى متغيرهاى جمعيتشناختى يكى از

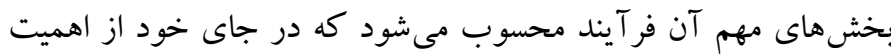

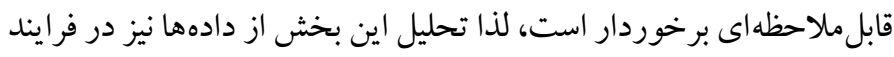

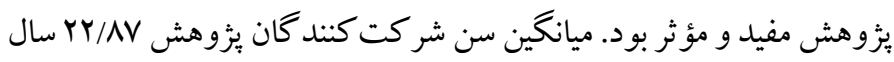

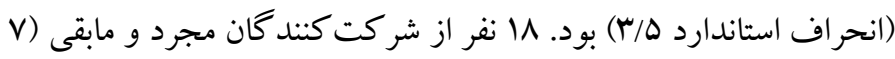

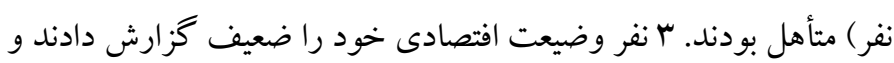
به ترتيب •r نفر و V نفر وضيعت اقتصادى خود را متوسط و خوب بيان

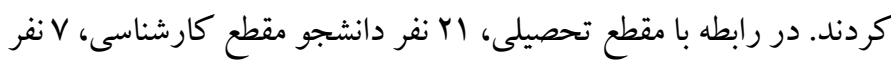
دانشجو مقطع كارشناسى ارشد و r نفر دانشجو مقطع دكترا بودند. ميانخين

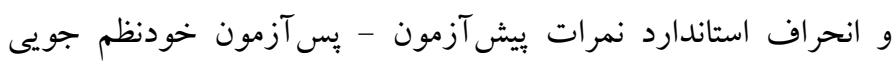

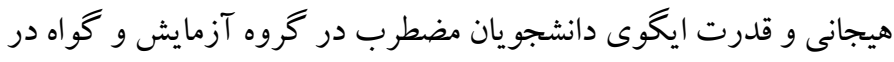


آن است كه بين گروهها در اين متغيرها تفاوت معنىدارى وجود دارد.

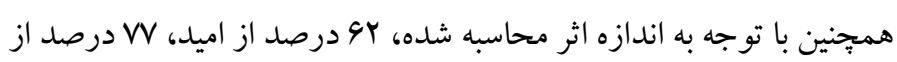

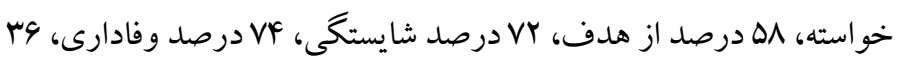
درصد عشق، NA درصد مراقبت، MV درصد ينهان كارى و 99 درصد از تغييرات تحمل ناشى از تأثير متغير مستقل بوده است؛ در نتيجه مىتوان بيان كرد كه اثربخشى درمان فراشناختى كروهى به طور معنى دارى باعث افزايش خودنظمجويى هيجانى و قدرت ايكوى دانشجويان مضطرب شده به است. با توجه به جدول سا، نتايج حاكى از تأثير متغير مستقل بر متغيرهاى وابسته بود؛ به عبارت ديخر زروههاى آزمايش و گو اه حداقل در يكى از متغير هاى خودنظمجويى هيجانى و قدرت ايخوى دانشجويان مضطرب تفاوت معنادارى دارند كه با توجه به اندازه اثر محاسبه شده، 9V درصد از كل واريانسهاى گروه آزمايش و كواه ناشى از اثر متغير مستقل است. همجنين توان آمارى آزمون برابر با ا است كه دلالت بر كفايت حجم نمونه است. اما براى تشخيص اينكه در كدام حيطهها تفاوت معنادار است، از آزمون تحليل كوواريانس تكك متغيرى در متن مانكووا استفاده شد كه نتايج آن در جدول F كزارش شده است.
معنادارى آزمون باكس از هـ/ • بيشتر است در نتيجه اين مفروضه برقرار است. همجينين نتايج آزمون خى دو بارتلت براى بررسى كرويت يا معنى دارى رابطه بين خودنظمجويى هيجانى و قدرت ايگگى دانشجويان df= مضطرب نشان داد كه رابطه بين آنها معنىدار است (1 (• > >

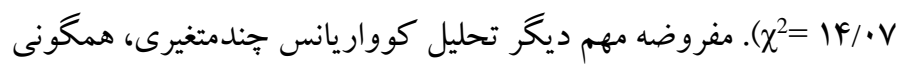
ضرايب رگرسيون است. لازم به ذكر است كه آزمون همكونى ضرايب ركرسيون از طريق تعامل متغيرهاى وابسته و متتغير مستقل (روش مداخله)

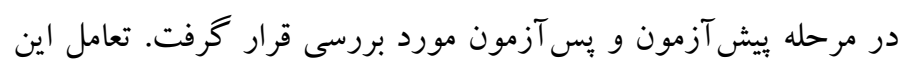
يشيش آزمونها و يس آزمونها با متغير مستقل معنادار نبوده و حاكى از همخونى شيب رگرسيون است؛ بنابراين اين مفروضه نيز برقرار است. با نئ توجه به برقرارى مفروضههاى تحليل كوواريانس جندمتغيرى، استفاده از اين آزمون مجاز خواهد بود. در ادامه به منظور بيى بردن به تفاوت گرووها، تحليل كوواريانس جند متغيره انجام شد (جدول ؟).

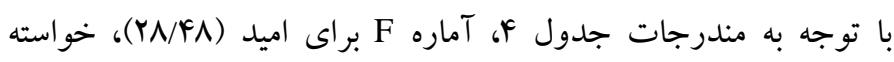

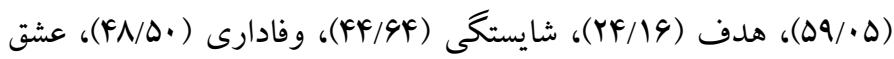
(9/AY)، مراقبت (

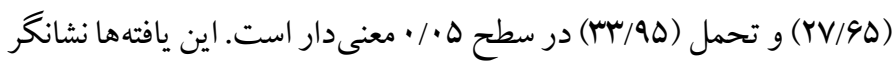

جدول r. آمارههاى توصيفى متغير هاى ثئوهش به تفكيك تروهها

\begin{tabular}{|c|c|c|c|c|c|c|}
\hline معنادارى & شاييرو - ويلكك & انحر اف استاندارد & ميانگين & مرحله & كروه & متغير ها \\
\hline$\cdot / 1 \cdot r$ & ./9४^ & $r / \mu$ & $r Y / 99$ & ييش آزمون & \multirow{2}{*}{ آزمايش } & \multirow{4}{*}{ اميد } \\
\hline - /DYD & $\cdot / 999$ & r/4q & rq/Dr & ֶِ آزمون & & \\
\hline •/ FrA & $\cdot / 999$ & $Y / Y F$ & rY/IT & يِيش آزمون & \multirow{2}{*}{ كواه } & \\
\hline$\cdot / \pi 49$ & . /9GY & $1 / \mu F$ & $r r / .4$ & يִ آزمون & & \\
\hline$\cdot / 11 F$ &.$/ Q F F$ & $r / \Delta Q$ & $r r / 4 G$ & ي يِش آزمون & \multirow{2}{*}{ آزمايش } & \multirow{4}{*}{ خواسته } \\
\hline$\cdot / 919$ & $\cdot / 919$ & $r / V I$ & rN/r. & يس آزمون & & \\
\hline.$/ 9 V r$ & $\cdot / 9 \vee \Delta$ & $r / 90$ & $r r / Y G$ & بيش آزمون & \multirow{2}{*}{ كواه } & \\
\hline$\cdot / 110$ & & r/৭9 & Tr/V & يس آزمون & & \\
\hline - rar &.$/ 9 \Delta 9$ & $r / \Delta F$ & rr/QT & بِيش آزمون & \multirow{2}{*}{ آزمايش } & \multirow{4}{*}{ هدف } \\
\hline $.19 \mathrm{VD}$ & $\cdot / 9 \vee \Delta$ & $1 / 49$ & $Y N / \cdot 9$ & ֵֶ آزمون & & \\
\hline$\cdot / M F$ & $\cdot / 9 F \Delta$ & $r / V Y$ & $r r / 91$ & بِيش آزمون & \multirow{2}{*}{ كواه } & \\
\hline • ror & $\cdot / 994$ & $\Gamma / 99$ & Yr/AS & يس آزمون & & \\
\hline$\cdot / r \Delta r$ & . /9GY & $r / F \Delta$ & $r \cdot / 41$ & يِيش آزمون & \multirow{2}{*}{ آزمايش } & \multirow{4}{*}{ شايستكى } \\
\hline $.19 \mathrm{~V}$ & $\cdot / 9 V Y$ & $r / q Q$ & TF/Tr & پِ آزمون & & \\
\hline$\cdot / 9 \wedge \mathrm{V}$ & - /ADF & $1 / 9$. & $r \cdot / T r$ & بيش آزمون & \multirow{2}{*}{ كواه } & \\
\hline$\cdot / 0 \cdot 1$ & - /AFD & $r / 94$ & $r \cdot / r r$ & پِ آزمون & & \\
\hline $.194 \mathrm{~V}$ &.$/ Q F V$ & $Y / F V$ & YI/FG & ييش آزمون & آزمايش & وفادارى \\
\hline
\end{tabular}




\begin{tabular}{|c|c|c|c|c|c|c|}
\hline معنادارى & شاييرو - ويلكك & انحراف استاندارد & ميانگين & مرحله & كروه & متغير ها \\
\hline$\cdot / \Lambda \Delta F$ & $.190 \mathrm{~V}$ & $1 / 90$ & $r q / T$. & يس آزمون & \multirow{3}{*}{ كواه } & \multirow{7}{*}{ عشق } \\
\hline$\cdot / 0 \cdot r$ & - /VFD & $r / \mu l$ & r & يِيش آزمون & & \\
\hline$\cdot / 9 \cdot 4$ &.$/ 99 \mathrm{~V}$ & r/aq & rI/Ir & يس آزمون & & \\
\hline $.199 \mathrm{~V}$ & $.19 \Delta \mathrm{V}$ & $r / Y V$ & $19 / 19$ & يِيش آزمون & \multirow{2}{*}{ آزمايش } & \\
\hline$\cdot 19 \cdot r$ & . / frq & $1 / 94$ & $r \mid / F i$ & پِ آزمون & & \\
\hline$\cdot / \mathrm{VIN}$ & .1949 & $r / F \Delta$ & $|\Delta / A|$ & بيش آزمون & \multirow{2}{*}{ كواه } & \\
\hline$\cdot / 994$ & $\cdot / \& V A$ & $r / \mu F$ & $19 / 49$ & يس آزمون & & \\
\hline . /OHV & $.19 \mathrm{Tr}$ & $1 / 90$ & YY/AS & يِش آزمون & \multirow{2}{*}{ آزمايش } & \multirow{4}{*}{ مر اقبت } \\
\hline.$/ 944$ & $\cdot / 914$ & $r / W$ & $r q / 1 r$ & پِ آزمون & & \\
\hline - /VFa & $\cdot / \mathrm{V} \Delta \Lambda$ & $r / 4 G$ & $r Y / F I$ & بِيش آزمون & \multirow{2}{*}{ كواه } & \\
\hline$\cdot / 9 \cdot r$ &.$/ 99 \mathrm{~V}$ & $r / \mu$ & $r r / Y q$ & بِ آزمون & & \\
\hline $.19 \mathrm{TV}$ & $\cdot 19 \cdot 1$ & $r / F V$ & $r r / q r$ & يِش آزمون & \multirow{2}{*}{ آزمايش } & \multirow{4}{*}{ خرد } \\
\hline - VDS & $\cdot / V \cdot q$ & $r / 9 r$ & $r q / 4 q$ & پِ آزمون & & \\
\hline - /1^9F & $\cdot / 9 F A$ & $r / I F$ & $r F / \Delta T$ & يِيش آزمون & \multirow{2}{*}{ كواه } & \\
\hline$\cdot / \Delta r$. & $\cdot / 499$ & $r / 99$ & TF/VT & بس آزمون & & \\
\hline$\cdot / 09 \Lambda$ & $\cdot / 4 \Delta Q$ & $1 / F r$ & $19 / 14$ & بيش آزمون & \multirow{2}{*}{ آزمايش } & \multirow{4}{*}{ ساز گارى } \\
\hline -/VAq & ./VA9 & $\mathrm{r} / \mathrm{VA}$ & $r T / T$ & يس آزمون & & \\
\hline.$/ 9 \mathrm{TV}$ & . & $1 / Y \Delta$ & $19 / 41$ & بيش آزمون & \multirow{2}{*}{ كواه } & \\
\hline$\cdot 19 \cdot r$ & $\cdot / 9 \cdot V$ & $r / \mu$ & $10 / \wedge 9$ & پِ آزمون & & \\
\hline$\cdot / v \cdot 1$ & $\cdot / \Lambda H_{F}$ & $1 / 9 \mathrm{~V}$ & $|V / F|$ & بيش آزمون & \multirow{2}{*}{ آزمايش } & \multirow{4}{*}{ ينهان كارى } \\
\hline.$/ 994$ & $\cdot / 4 \cdot q$ & $r / \Delta r$ & $Y F / .4$ & پِ آزمون & & \\
\hline$\cdot / A \cdot \Delta$ & .1949 & $r / \mu \Lambda$ & $1 / / F$. & يِش آزمون & \multirow[t]{2}{*}{ كواه } & \\
\hline$\cdot / N+1$ & $\cdot / F \vee \Lambda$ & $r / 91$ & $|V / r|$ & پِ آزمون & & \\
\hline$\cdot / 9 \cdot V$ & $\cdot / A Y F$ & $1 / 4 r$ & N/YG & ييش آزمون & \multirow{2}{*}{ آزمايش } & \multirow{4}{*}{ تحمل } \\
\hline$\cdot / 9 \cdot \Delta$ & $\cdot / \mathrm{V} / 9$ & $r / V^{e}$ & $1 \% / .9$ & ي" آزمون & & \\
\hline • pir & $\cdot / 9 \cdot 1$ & $r / 9 r$ & $N / 91$ & ييش آزمون & \multirow[t]{2}{*}{ كواه } & \\
\hline$\cdot 19 \cdot 4$ & $\cdot / 9 k T$ & $1 / 4 \Delta$ & $N \cdot V$ & يس آزمون & & \\
\hline
\end{tabular}

جدول ". نتايج تحليل كوواريانس جندمتغيرى بر روى ميانتين نمرات بـ آزمون

\begin{tabular}{|c|c|c|c|c|c|}
\hline مجذور اتا & سطح معنادارى & $\mathrm{F}$ & مقدار & آزمونها & منابع تغييرات \\
\hline$\cdot / 9 \mathrm{~V}$ &.$/ \cdot 1$ & rG/VI & $\cdot / 9 V V$ & آزمون اثر ييلايى & \multirow{4}{*}{ كروه } \\
\hline.$/ 9 V$ &.$/ . .1$ & rQ/NI & . & آزمون لامبداى ويلكز & \\
\hline$\cdot / 9 V$ &.$/ . .1$ & rQ/NI & $F \mid / 91$ & آزمون اثر هتلينك & \\
\hline$\cdot / 9 \mathrm{~V}$ & $\cdot / . .1$ & re/NI & $F \mid / 9 \Lambda$ & آزمون بزر گكترين ريشه روى & \\
\hline
\end{tabular}

جدولع. نتايج حاصل از تحليل كوواريانس تك متغيرى بر روى ميانگين نمرههاى يسآزمون متغيرهاى وابسته در دو كروه آزمايش و كواه

\begin{tabular}{|c|c|c|c|c|c|c|c|}
\hline توان آمارى & اندازهُ اثر & معنادارى & Tمارة F & ميانگين مجذورات & Df & مجموع مجذورات & متغيرهاى وابسته \\
\hline.$/ 99$ &.$/ 94$ &.$/ . \cdot 1$ & YN/FA & Fr/DI & 1 & $F Y / D I$ & اميد \\
\hline 1 & $\cdot / \mathrm{VV}$ &.$/ . \cdot 1$ & $\Delta q / \cdot \Delta$ & $V \cdot / F A$ & 1 & $V \cdot / F A$ & خواسته \\
\hline.$/ 99$ & $\cdot / \Delta \Lambda$ &.$/ \cdot 1$ & $r F / 19$ & $r \Delta / 1 Y$ & 1 & $F \Delta / I T$ & هدف \\
\hline 1 & $\cdot / V Y$ &.$/ . .1$ & $F F / q F$ & $F F / Q F$ & 1 & $F F / a F$ & شايستخى \\
\hline 1 & $\cdot / V^{F}$ &.$/ . .1$ & $F N / \Delta$. & $\Lambda 1 / N$ & 1 & $\Lambda 1 / V r$ & وفادارى \\
\hline
\end{tabular}




\begin{tabular}{|c|c|c|c|c|c|c|c|}
\hline توان آمارى & اندازة اثر & معنادارى & Tارة & ميانخين مجذورات & Df & مجموع مجذورات & متغيرهاى وابسته \\
\hline$\cdot / \mathrm{AF}$ &.$/ 149$ & .1 .99 & $9 / \wedge \mu$ & $\Delta 1 / 1 F$ & 1 & $\Delta I / / F$ & عشق \\
\hline 1 & $\cdot|A|$ &.$/ .1$ & $V Y / V^{F}$ & $|F 9 / V|$ & 1 & $|F G / V|$ & مراقبت \\
\hline$\cdot / \wedge \Delta$ & $\cdot / T V$ &.$/ .1$ & $1 \cdot / F_{F}$ & RT/AD & 1 & $\kappa r / \Lambda \Delta$ & خرد \\
\hline 1 & - /AF &.$/ \cdot 1$ & $9 Y / Q$. & ITN/IT & 1 & IrN/IT & ساز كارى \\
\hline.$/ 99$ & .191 &.$/ .1$ & $r V / 90$ & $194 / \Delta$. & 1 & $19 r / \Delta$. & ينهان كارى \\
\hline 1 & .194 & $\% \cdot 1$ & $M / 9 \Delta$ & $9 \Lambda / \cdot 1$ & 1 & $9 \Lambda / \cdot 1$ & تحمل \\
\hline
\end{tabular}

ييامدهاى قدرت ايكوست (يرويز و همكاران، هوسا). در اين راستا، درمان

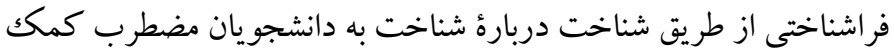

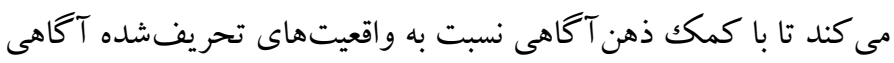

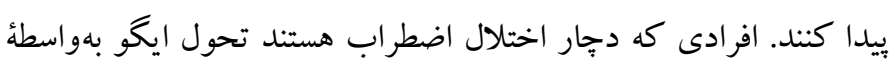

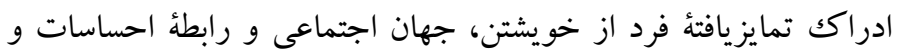

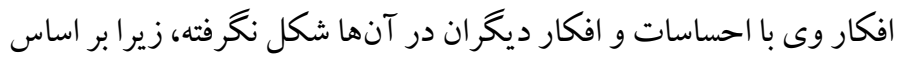

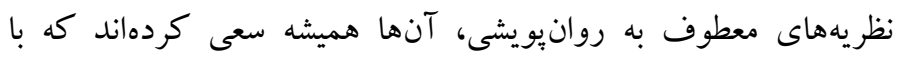
اضطراب خود مقابله كنند و هيج تلاشى در جهت شناخت افكار و احساسات خود، ديخران، جهان اجتماعى و بيرامون خود نمى كنند، درمان

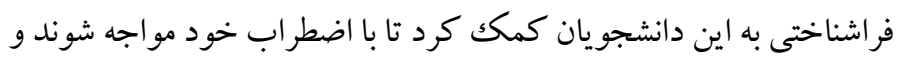
با قضاوت و ارزيابى اضطراب خود سبب تحول در ايگوى خودشان شوند. ״ِ درنتيجه، درمان فراشناختى به اين دانشجويان كمكك كرد تا اطلاعات

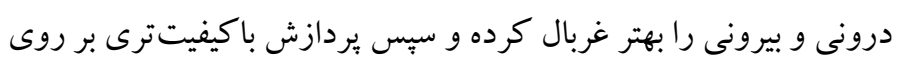

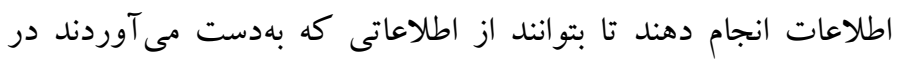
موقعيتهاى مختلف استفاده كنند تا حس واقعيتسنجى خود را بهبود

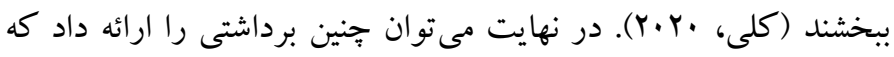

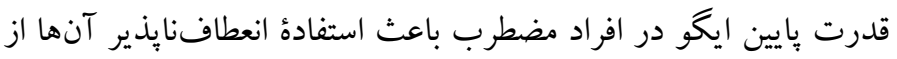
مكانيزمهاى دفاعى مىشود. اما درمان فراشناختى با اصلاح و تعديل

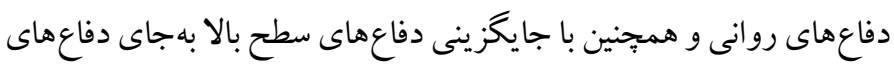
سطح يايين موجب بهبود عملكرد ايخو در افر اد مضطرب مى شود دود (كوتيوال

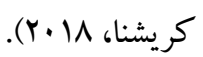
از سويى ديخر، يافتهاى اين يزوهش نشان داد درمان فراشناختى گروهى بر روى خودنظمجويى هيجانى دانشجويان مضطرب اثر كذار بوده است و باعث شد در يس آزمون خودنظم جويى هيجانى دانشجويان مضطرب روب

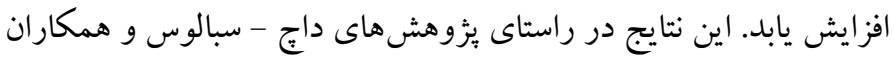

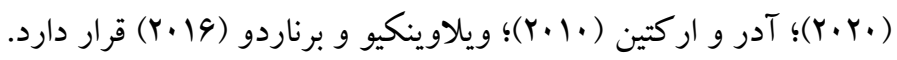

\section{بحث و نتيجه تيرى} يُروهش حاضر با هدف تعيين اثربخشى درمان فراشناختى بر روى خودئى

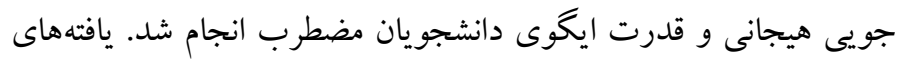

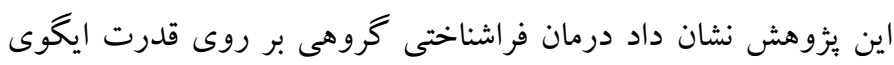

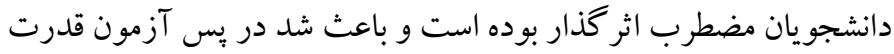

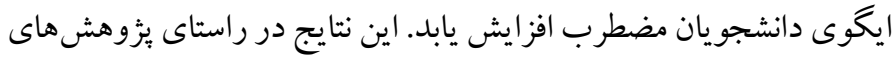

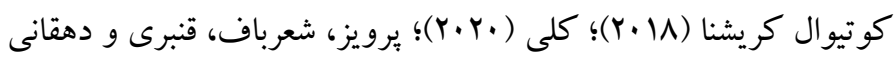

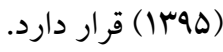
اين يافته را با استناد به اين نكته كه فراشناخت نيازمند ذهن آكاهى است و و ودار

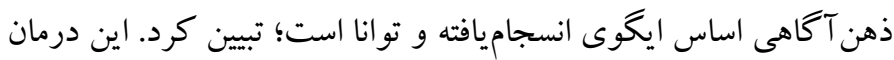
با آموزش ذهن آكاهى و افزايش شناخت در مورد فر آيندهاى روانى

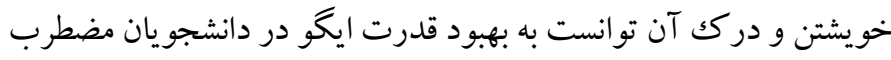

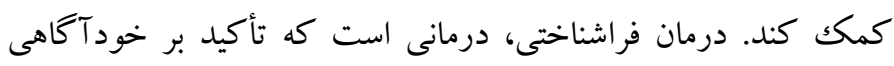
هيجانى دارد و معتقد است افراد مىتواند بسيارى از شناختها، افكار و حتى محتويات ناخودآكاه را بهصورت خودآكاه دربياورند، ازاينرو مى تو اند درمان مناسبى بر ایى اثربخشى بر روى قدرت ايخوى افر افر اد مضطرب

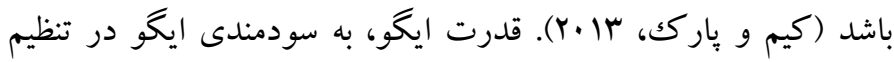

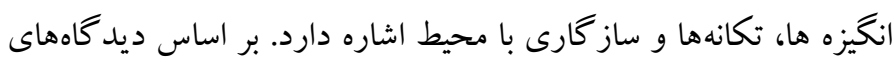

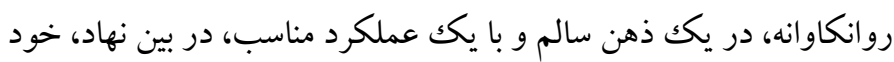

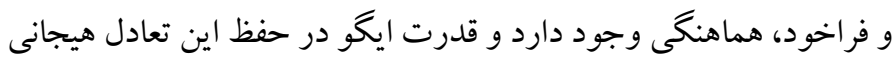

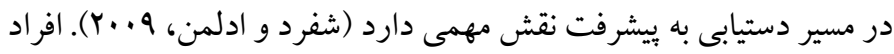

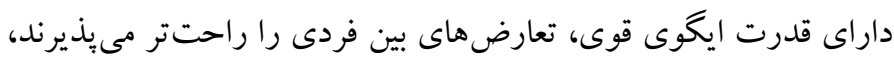

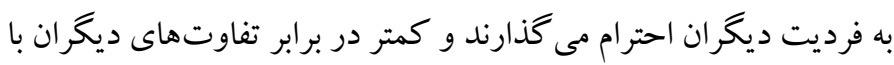

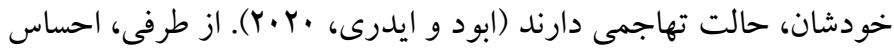
خودبسندگى در حيطة شخصى و اجتماعى در روبهرو شدن با عوامل استرسزاى محيطى و تحمل استرس بدون تجربهُ اضطراب فلج كننده از 
واكنشهاى افراد است (ويويان و همكاران، 19 اب). به همين دليل، افرادى

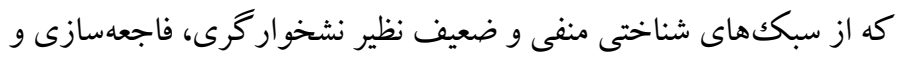

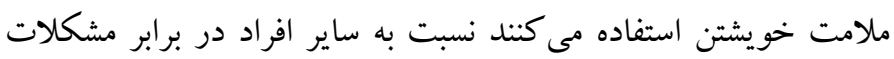

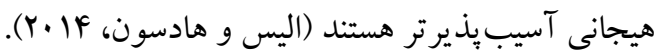

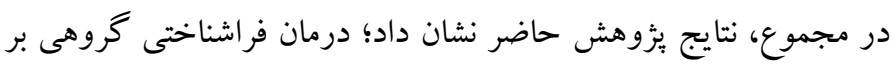
روى قدرت ايگو و خودنظمجويى هيجانى دانشجويان مضطرب اثر گذار

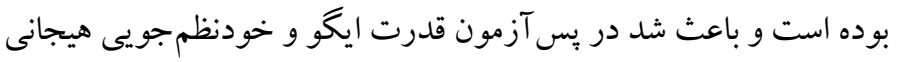
دانشجويان مضطرب افزايش يابد. در واقع مىتوان اذعان داشت درمان

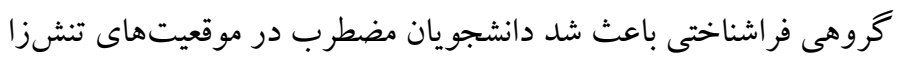
و اضطرابآور نسبت به هيجانهاى خودآكاهى بيشترى داشته باشند. همجنين به افراد مضطرب كمك كرد تا در جهت شناخت افكار و احساسات خود و ديخران گام بردارند.

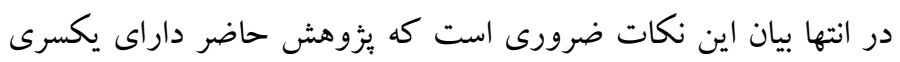
محدوديتها است. جامعه آمارى اين يزّوهش دانشجويان دانشگاههاى

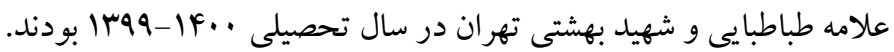

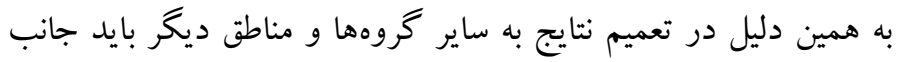

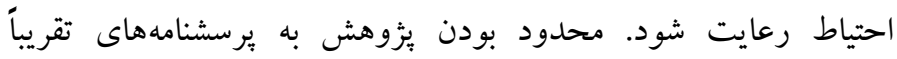

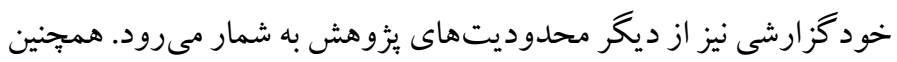
از عدم كنترل عوامل مز احمى همجون همجيون شرايط زيستى، اجتماعى،

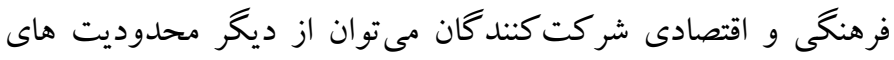

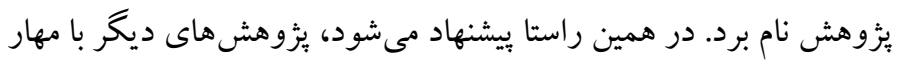
و بررسى بيشتر متغيرهاى بالا از طريق بررسى نقش ميانجى يا تعديل

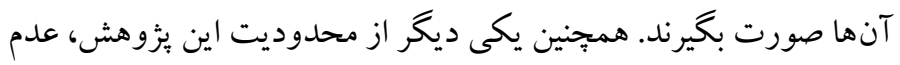

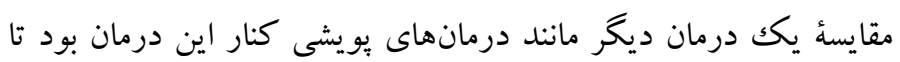

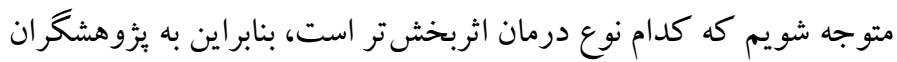
يشنهاد مىشود كه يكك درمان ديخر را نيز كنار درمانى كه انتخاب مى كنند مدنظر داشته باشند تا اثربخشتربودن درمانها را هم مورد بررسى قرار
اين نتايج را مى توان با توجه به دو راهبرد هيجانمدار و مسئلهدار لازاروس

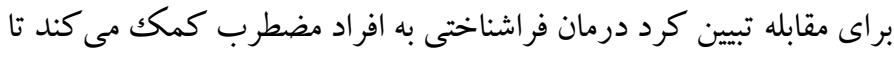

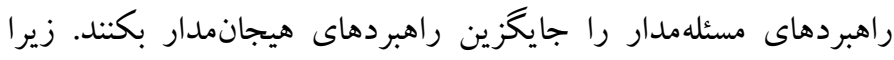

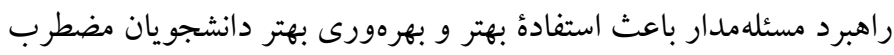

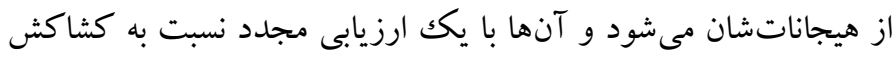

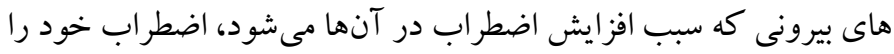
مديريت كرده و اجازه نمىدهند كه ميزان اضطراب آنها بـ آنها از سطح معيار

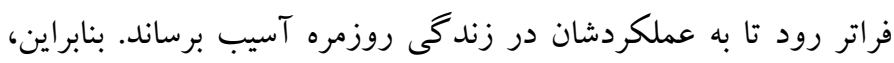

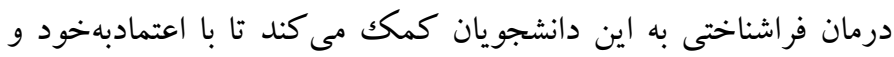

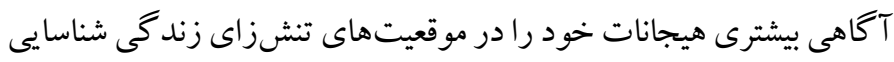

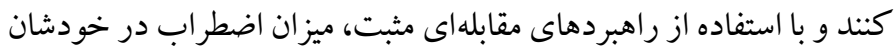

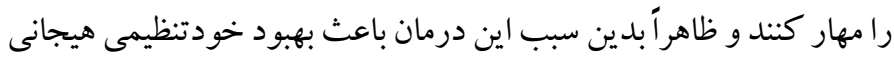

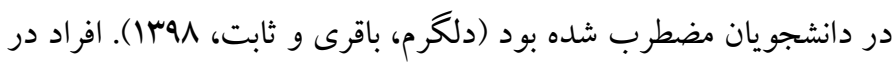
مو اجهه با شرايط استرسزا از راهبردهاى متنوعى استفاده مى كنند. از جمله

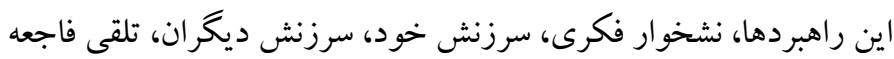

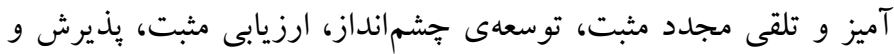

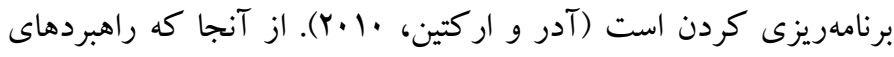

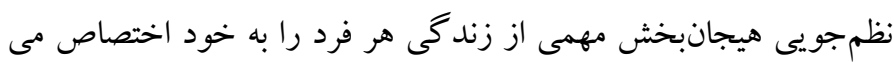

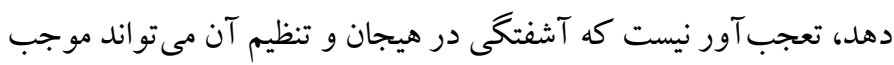

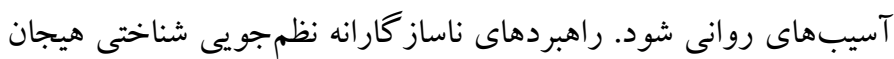

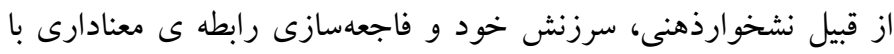

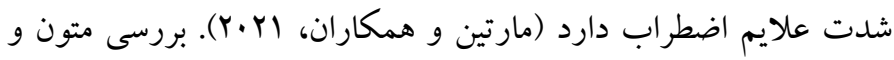

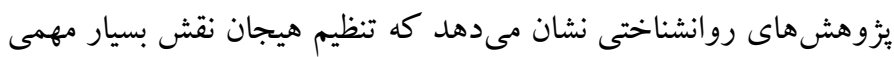

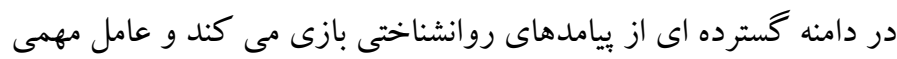

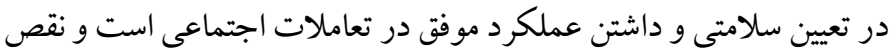

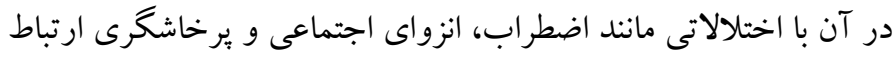

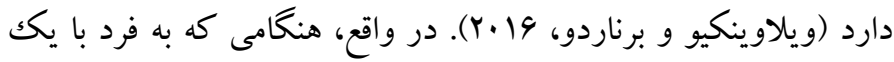
موقعيت هيجانى روبرو مىشود احساس خوب و خوشينى براى كنترل هيجان كافى نيست بلكه وى نياز دارد كه در اين موقعيتها بهتر ين كار كرد شناختى نيز داشته باشد. در اصل در تنظيم هيجان به تعامل بهينهاى از شناخت و هيجان جهت مقابله با شرايط منفى نياز است؛ زيرا انسانها با هر جه مواجه مىشوند آن را تفسير مى كنند و تفسيرهاى شناختى تعيين كننده 
نقش هر يك از نويسـند كان: نويسـنده نخسـت، مسـوليت دريافت مجوز، اجراى

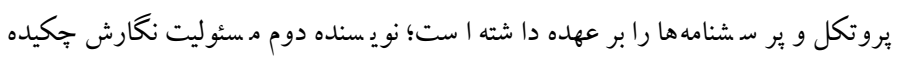

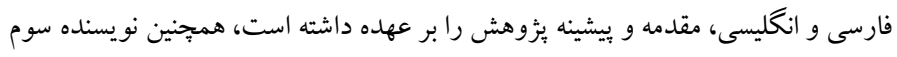

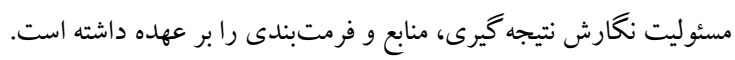

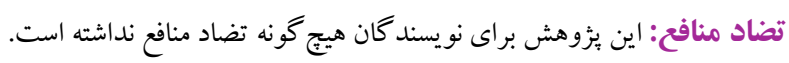

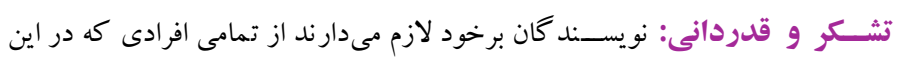
يُروهش مشار كت و همكارى داشتند، تشكر و قدردانى نمايند.

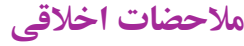

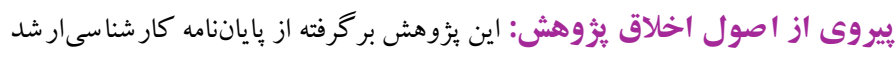

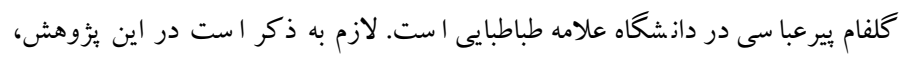

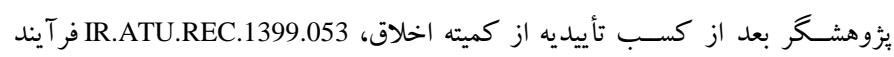
تحقيق را انجام داد. حامى مالى: اين مطالعه بدون حمايت مالى هيج مؤ سسه و سازمان دولتى يا خصو صى ادي انجام شده است. 


\section{References}

Ader, E., \& Erktin, E. (2010). Coping as self-regulation of anxiety: A model for math achievement in highstakes tests. Cognition, Brain, Behavior, 14(4), 311. [Link]

Abbasi A, Aghaei A, Ebrahimi Moghadam H. (2019). Effectiveness of metacognitive therapy on resiliency in the people with generalized anxiety. $J$ of Psychological Science, 18(78), 691-698. (Persian). [Link]

Adesola, S. A., \& Li, Y. (2018). The relationship between self-regulation, self-efficacy, test anxiety and motivation. International Journal of Information and Education Technology, 8(10), 759-763. [Link]

Abood, M. H., \& Idri, N. (2020). The Relationship between Religious Commitment and Ego Strength among a Sample of Hashemite University Students. Journal of Educational and Psychological Studies [JEPS], 14(3), 398-416. [Link]

Antony, M. M., Coons, M. J. Mccabe, R. E. Ashbaugh, A., \& Swinson, R. P. (2006). Psychometric properties of the social phobia inventory: Further evaluation. Behaviour Research and Therapy, 44, 1177-85. [Link]

Duch-Ceballos, C., Oliver Pece, J., \& Skowron, E. (2020). Differentiation of Self and Its Relationship with Emotional Self-Regulation and Anxiety in a Spanish Sample. The American Journal of Family Therapy, 1-17. [Link]

Delgarm, H., Bagheri, N., Sabet, M. (2019). The relationship between emotional self-regulation and resilience with coping style for stress in university students. Thoughts and Behavior in Clinical Psychology, 14(52), 67-76. (Persian). [Link]

Ellis, D. M., \& Hudson, J. L. (2014). The meta cognitive model of generalized anxiety disorder in children and adolescents. Cognitive and Behavioral Practice, 13(4), 151-163. [Link]

Englert, C., Zwemmer, K., Bertrams, A., \& Oudejans, R. R. (2015). Ego depletion and attention regulation under pressure: Is a temporary loss of self-control strength indeed related to impaired attention regulation? Journal of Sport and Exercise Psychology, 37(2), 127-137. [Link]

Einy S, narimani $M$, atadokht A, basharpoor S, Sadeghi Movahhed F. (2018). Effectiveness of CognitiveAnalytical Therapy on Ego-Strength and Object Relations of Persons With Borderline Personality Disorder. Stud Med Sci, 29 (1), 1-11. (Persian). [Link]
Farahani, Zahra (2011). Ego power, defense styles and thematic relationships of drug addicts and nonaddicts (Master Thesis). Al-Zahra University, Tehran. (Persian). [Link]

Goger, P., Rozenman, M., \& Gonzalez, A. (2020). The association between current maternal psychological control, anxiety symptoms, and emotional regulatory processes in emerging adults. Journal of Behavior Therapy and Experimental Psychiatry, 6(2), 101563. [Link]

Hossein Kaviani H, Mousavi A S. (2008). Psychometric property of the Persian version of Beck Anxiety Inventory (BAI). Tehran Univ Med J, 66 (2), 136140. (Persian). [Link]

Kinniburgh, K. J., Blaustein, M., Spinazzola, J., \& Van der Kolk, B. A. (2017). Attachment, self-Regulation, and competency: A comprehensive intervention framework for children with complex trauma. Psychiatric Annals, 35(5), 424-430. [Link]

Kothival Krishna, P. (2018). Anxiety and Ego Strength in College Students. International Journal of Research and Analytical Reviews, 5(1), 162-164. [Link]

Kelly, W. E. (2020). Nightmares and ego strength revisited: Ego strength predicts nightmares above neuroticism and general psychological distress. Dreaming, 30(1), 29. [Link]

Kim, S. Y., \& Park, B. J. (2013). Development and validation of the ego strength scale for children. Family and Environment Research, 51(5), 537-549. [Link]

Markstrom, C. A., Sabino, V. M., Turner, B. J., \& Berman, R. C. (1997). The psychosocial inventory of ego strengths: Development and validation of a new Eriksonian measure. Journal of Youth and adolescence, 26(6):705-732. [Link]

Mishra, V. (2013). A study of self-concept in relation to ego-strength of sighted and visually impaired students. International Journal on New Trends in Education and Their Implications, 4(1), 203-207. [Link]

Martín, J. C., Ortega-Sánchez, D., Miguel, I. N., \& Martín, G. M. G. (2021). Music as a factor associated with emotional self-regulation: A study on its relationship to age during COVID-19 lockdown in Spain. Heliyon, 7(2), e06274. [Link]

Najarzadegan F, Farhadi H. The effectiveness of qualityof-life therapy on communication skills, addiction to cyberspace, marital satisfaction, and emotional self-regulation in couples. $J$ of Psychological Science, 18(74), 247-256. (Persian). [Link] 
Parviz K, Aghamouhamadian Sharbaf H, Ghanbarihashemabadi B, Dehghani M. (2016). The relationship between ego strength and metacognition among male and female students. Educ Strategy Med Sci, 9 (2), 118-126. (Persian). [Link]

Rahmani S, Rahmati A, kazemi rezaei A, Pishgahi B. (2020). The effectiveness of self-compassion therapy on cognitive emotion regulation strategies and anxiety sensitivity in female nurses. IJPN, 8 (4), 99-110. (Persian). [Link]

Shakarami, M., latifi, Z., mosavi, S. (2020). The Effectiveness of Compassion Focused Group Therapy on Aggression, Emo-tion of SelfRegulation and School Motivation about the Boy Student of the El-ementary School. Research in School and Virtual Learning, 7(2), 77-87. (Persian). [Link]

Safikhani Gholizadeh S, Mahmoudi A. (2019). The Effectiveness of Metacognitive Therapy in a Group Method on Metacognitive Beliefs in Female Students with Social Anxiety Disorder. Armaghane danesh, 24 (3), 540-554. (Persian). [Link]

Sobański, J. A., Klasa, K., Müldner-Nieckowski, Ł., Dembińska, E., Smiatek-Mazgaj, B., \& Rodziński, P. (2018). Changes in ego strength in patients with neurotic and personality disorders treated with a short-term comprehensive psychodynamic psychotherapy. Psychiatr Pol, 52(1), 115-27. [Link] Shepherd, R. M., \& Edelman, R. J. (2009). The Interrelationship of Social Anxiety with Anxiety, Depression, Locus of Control, Ways of Coping and Ego Strength amongst University Students. College Quarterly, 12(2), n2. [Link]

Vivian, E., Oduor, H., Arceneaux, S. R., Flores, J. A., Vo, A., \& Madson Madden, B. (2019). A cross-sectional study of perceived stress, mindfulness, emotional self-regulation, and self-care habits in registered nurses at a tertiary care medical center. SAGE Open Nursing, 5, 2377960819827472. [Link]

Wells, Adrienne (2012). Metacognitive therapy for anxiety and depression. (Translated by Mehdi Akbari). Tehran: Arjmand. (Persian). [Link] 